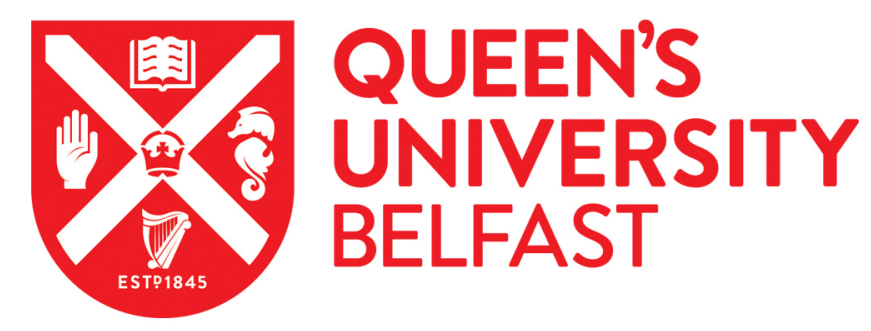

\title{
Synthesis, Characterization, and Drug Delivery Application of Self- assembling Amphiphilic Cyclodextrin
}

Patel, M. R., Lamprou, D. A., \& Vavia, P. R. (2019). Synthesis, Characterization, and Drug Delivery Application of Self-assembling Amphiphilic Cyclodextrin. AAPS PharmSciTech, [11].

\section{Published in:}

AAPS PharmSciTech

\section{Document Version:}

Peer reviewed version

Queen's University Belfast - Research Portal:

Link to publication record in Queen's University Belfast Research Portal

Publisher rights

( ) American Association of Pharmaceutical Scientists 2019. This work is made available online in accordance with the publisher's policies. Please refer to any applicable terms of use of the publisher.

\section{General rights}

Copyright for the publications made accessible via the Queen's University Belfast Research Portal is retained by the author(s) and / or other copyright owners and it is a condition of accessing these publications that users recognise and abide by the legal requirements associated with these rights.

Take down policy

The Research Portal is Queen's institutional repository that provides access to Queen's research output. Every effort has been made to ensure that content in the Research Portal does not infringe any person's rights, or applicable UK laws. If you discover content in the Research Portal that you believe breaches copyright or violates any law, please contact openaccess@qub.ac.uk. 


\title{
Synthesis, characterization and drug delivery application of self- assembling amphiphilic cyclodextrin
}

\author{
Mayank R. Patel ${ }^{a}$, Dimitrios A. Lamprou ${ }^{b, c}$, Pradeep R. Vavia $^{a, *}$ \\ a Department of Pharmaceutical Sciences and Technology, Institute of Chemical Technology, University under \\ Section 3 of UGC Act - 1956, Elite Status and Centre of Excellence - Govt. of Maharashtra, TEQIP Phase III Funded, \\ Matunga (E), Mumbai - 400019, India. \\ ${ }^{\mathrm{b}}$ Strathclyde Institute of Pharmacy and Biomedical Sciences (SIPBS), University of Strathclyde, 161 Cathedral Street, \\ Glasgow, G4 0RE, United Kingdom. \\ c School of Pharmacy, Queen's University Belfast, 97 Lisburn Road, Belfast, BT9 7BL, United Kingdom.
}

\author{
*Corresponding Author: \\ Prof. Pradeep R. Vavia, \\ Center for Novel Drug Delivery Systems, \\ Department of Pharmaceutical Sciences and Technology, \\ Institute of Chemical Technology, \\ N. P. Marg, Matunga (E), \\ Mumbai - 400 019. India. \\ Tel No.: +912233612220 \\ Fax No.: +9122 24145614 \\ Email: pr.vavia@ictmumbai.edu.in
}

Running head: Self-assembling amphiphilic-CD nanovesicles 


\begin{abstract}
aAbstract
The main aim of the research was to synthesize amphiphilic cyclodextrin (AMCD) by substituting C12 alkyl chain to a $\beta$-cyclodextrin $(\beta C D)$ in a single step and to study its self-assembly in an aqueous medium. The drug delivery application of the AMCD was also evaluated by encapsulating tamoxifen citrate as a model hydrophobic drug. AMCD was able to self-assemble in aqueous media; forming nanovesicles of size <200 nm, capable of encapsulating Tamoxifen Citrate (TMX). Molecular docking and MD simulation studies revealed the interaction between TMX and AMCD which formed a stable complex. TEM and AFM studies showed that nanovesicles were perfectly spherical having a smooth surface and a theoretical AMCD bilayer thickness of $\sim 7.2 \mathrm{~nm}$ as observed from SANS studies. XRD and DSC studies revealed that TMX was amorphized and molecularly dispersed in AMCD bilayer which was released slowly following Fickian diffusion. AMCD has excellent hemocompatibility as opposed to $\beta C D$ and no genotoxicity. $\mathrm{IC}_{50}$ of TMX against MCF-7 cell lines was significantly reduced from $11.43 \mu \mathrm{g} / \mathrm{ml}$ to $7.96 \mu \mathrm{g} / \mathrm{ml}$ after encapsulation in nanovesicle because of nanovesicles being endocytosed by the MCF-7 cells. AMCD was well tolerated by IV route at a dose $>2000 \mathrm{mg} / \mathrm{kg}$ in rats. Pharmacokinetic profile of TMX after encapsulation was improved giving 3-fold higher AUC; extended mean residence time is improving chances of nanovesicle to extravasate in tumor via EPR effect.
\end{abstract}


Keywords: Amphiphilic cyclodextrin; nanovesicles; bilayer; molecular modelling; cytotoxicity 


\section{INTRODUCTION}

In recent decades, nanotechnology has been put to an application in the drug delivery arena very profoundly $(1,2)$. There are numbers of nanotechnology-based products which are getting approved worldwide. To name a few, nanosuspensions, nanocrystals, polymeric nanoparticles, lipidic nanoparticles, SMEDDS, microemulsion, nanoemulsions, liposomes are nano-systems which are clinically approved. However, there are many hurdles in exploring the full potential of nanotechnology in drug delivery. Most of the systems require complex processing to achieve nano size, which poses difficulty in scaling up the process and maintaining the reproducibility $(3,4)$. Few systems are fairly simple and scalable, such as SMEDDS that require a very high amount of surfactants which limits its applications. Liposomes are one of the most successful nano-systems to date. The popularity of liposomes is due to its selfassembling nature and capability to encapsulate both hydrophobic and hydrophilic drugs. Nevertheless, liposomes suffer serious limitations due to their chemical instability, low drug loading capacity, drug leakage, and complex processing. All these reasons encouraged scientists to look for various other self-assembling systems for drug delivery applications.

Cyclodextrins (CD) are cyclic oligosaccharides formed by $(\alpha-1,4)$-linked $\alpha$-d-glucopyranose units. They are obtained by enzymatic degradation of starch, with $\alpha, \beta$, and $\gamma$ been the three native types of cyclodextrin with 6,7 , and $8 \alpha$-dglucopyranose units, respectively (5). CDs have been used for decades in the pharmaceutical industry to enhance the solubility, stability, and bioavailability of the active pharmaceutical ingredients (6-8). Native CD has more hydrophilic exterior and a less hydrophobic, less-polar cavity (the dielectric constant of the cavity is close to the $40 \%$ ethanol/water mixture) (9) with advantages like forming molecular inclusion with hydrophobic drugs. Several modifications are reported by various scientist in which they crosslinked cyclodextrin with the help of bifunctional crosslinkers and form a network of nanopores; this material is coined as cyclodextrin nanosponges (10). Application of nanosponges were reported by many groups for delivery of actives such as Camptothecin (11), Resveratrol (12), Erlotinib (13), Tamoxifen (14) etc. However, it is problematic for hydrophilic CD molecule and such crosslinked CD nanosponges to interact with the biological membrane, which is lipophilic in nature $(7,15)$. A novel class of modified CD called amphiphilic cyclodextrins (AMCD) in which hydroxyl (-OH) groups of cyclodextrin was substituted with hydrophobic alkyl chains of different lengths had been reported (16-18). These type of chemical modifications can achieve many goals at once, such as: altering their water solubility, reducing the nephrotoxicity and hemolysis encountered on intravenous (IV) administration, facilitate the interaction with biological membranes, self-assembles to form different nanostructure like nanosphere, nanoparticle, and nanocapsules depending on the method of preparation and their components to encapsulate drug molecule (15). Many scientists have reported series of molecules obtained by grafting different substitutions selectively on either primary or secondary face of cyclodextrins via ether, ester or amide linkage (19-22) and studied their application as a drug carrier. Drug leakage is a major disadvantage of many nanocarriers, whereas amphiphilic cyclodextrin can form an inclusion complex with drug molecules and stabilize them in a self-assembled nanocarrier solving a problem of drug leakage.

In the present research, we synthesized AMCD by randomly alkylating hydroxyl groups of beta-cyclodextrin $(\beta C D)$ with $\mathrm{C} 12$ alkyl chain. Based on the biochemical and nutritional evidence $\mathrm{C} 12$ acid has distinctive properties that are 
not shared with other medium and long long-chain fatty acids. Lauric acid is better managed by the body and is quickly metabolized by the body as compared to other saturated fatty acids. Literature also suggests Lauric acid is less accumulated in body as bad cholesterol as compared to other saturated fatty acids. In fact, it improves the ratio of total cholesterol/HDL, which is good for the body (23). Having distinct benefits over other medium and long-chain fatty acids, authors have selected Lauric acid for the substitution. Author is focusing on bouquet type of amphiphilic cyclodextrin with approximately 7 alkyl chain on both primary and on the secondary rim of $\beta C D$ and for this Lauric acid/ $\beta C D$ ratio was selected as 15 . The synthesized $A M C D$ was thoroughly characterized, and the safety profile was established by various in vitro and in vivo tests. The morphology of self-assembled nanovesicles was evaluated using the various advanced microscopic technique (e.g., AFM, TEM, SANS). Tamoxifen citrate (TMX) being class BCS class II moiety having poor solubility in water, and having structure prefect for cyclodextrin complexation; less than 5 condensed rings and a molecular weight between 100-400 Dalton (24) is selected as a model drug. TMX is available in a tablet form for oral administration. However, it has severe dose dependent side effects such as endometrial hyperplasia, liver cancer, increase blood clotting, retinopathy etc. Thus, many scientists have proposed a colloidal delivery system for sustain release of TMX via parenteral route for passive targeting to the tumor via EPR effect such as PLGA based nanoparticles (25), Solid lipid nanoparticles (26), microemulsion (27), sustain release liposomes(28) etc. Interaction of TMX with synthesized AMCD was assessed by in-silico molecular docking and MD simulation studies. In vitro cytotoxicity and in vivo pharmacokinetics of TMX was assessed to understand the changes, if any, due to encapsulation in nanovesicles. In addition, flow cytometry and confocal study were conducted to evaluate the uptake of nanovesicles in MCF-7 cell line.

\section{MATERIALS AND METHODS}

\section{Materials}

Tamoxifen citrate was obtained from ArEx Laboratories (Mumbai). $\beta C D$ was obtained from Roquette, India. Lauroyl chloride was purchased from (Merck-Sigma Aldrich, USA). Triethylamine (TEA), dry N, N-dimethylformamide (Dry DMF), dichloromethane (DCM), and other HPLC grade solvents were purchased from Merck, India. Kolliphor P 407 was procured from BASF, India. Mannitol (Perlitol ${ }^{\mathrm{TM}}$ ) was obtained from Signet Corporation, India. Dialysis membrane of the molecular weight cut off 12-14 kDa was purchased from Hi-media, India. MCF-7 cells were procured from ATCC, and HDMEC cells were procured from PromoCell GmbH. [3-(4,5-dimethylthiazol-2-yl)-2,5diphenyltetrazolium bromide] (MTT) were purchased from Invitrogen. Freshly prepared double distilled water and buffers filtered through $0.22 \mu \mathrm{m}$ membrane filter (Merck Millipore, India) was used where ever required.

Synthesis and characterization of Amphiphilic Cyclodextrin (AMCD)

\section{Synthesis}

Synthesis scheme is presented in figure 1 . Briefly, $\beta C D$, due to high water content was dried at $60^{\circ} \mathrm{C}$ in a vacuum oven for $24 \mathrm{hrs}$ before use. Special dry DMF with water content $<0.01 \%$ was stored under nitrogen with molecular sieves $\left(1 \mathrm{~A}^{\circ}\right) .1$ mole of dry $\beta C D$ was solubilized in DMF under nitrogen. Further, $\mathbf{1 5}$ moles of triethylamine was 
added, and the solution was kept for stirring in an ice bath. When the solution became clear, 15 moles of Lauroyl chloride was added dropwise in the solution under constant stirring in an ice bath. Next, the temperature of the reaction was raised to $30{ }^{\circ} \mathrm{C}$ and stirred for $24 \mathrm{~h}$ in a nitrogen environment. The reaction was monitored by thin layer chromatography (TLC) (DCM: Methanol 50:50, $\mathrm{Rf}=0.7$ ). After $24 \mathrm{~h}$, the product was precipitated in ice-cold water $(\mathrm{pH} 2)$ to neutralize any unreacted triethylamine. The product was filtered and washed thrice with ice-cold water $(\mathrm{pH}$ 2) to remove triethylamine traces. Finally, the product was solubilized in DCM and filtered to remove unreacted $\beta C D$. AMCD was recovered by vacuum drying.

\section{Spectroscopic Characterization}

AMCD was characterized using Fourier Transformed Infrared Spectroscopy (FTIR), Differential Scanning Calorimetry (DSC) and ${ }^{1} \mathrm{H}$ and ${ }^{13} \mathrm{C}$ Nuclear Magnetic Resonance (NMR) spectroscopy. Molecular weight and degree of substitution were evaluated using Matrix Assisted Laser Desorption Ionization coupled with Time of Flight detector (MALDI-TOF) and elemental analysis.

FTIR spectra of $\beta C D$ and AMCD were recorded on Shimadzu FT-IR spectrophotometer using $\mathrm{KBr}$ discs. The instrument was operated under dry air purge, and the scans were collected at scanning speed of $2 \mathrm{~mm} \mathrm{sec}^{-1}$ with a resolution of $4 \mathrm{~cm}^{-1}$ and an interval of $1 \mathrm{~cm}^{-1}$ over the region of $4000-400 \mathrm{~cm}^{-1}$.

The DSC curves were recorded on Differential Scanning calorimeter (DSC1, Mettler Toledo). The thermal behavior was studied by heating samples $(\sim 10 \mathrm{mg})$ in sealed aluminum pans, using the empty aluminum pan as a reference, over a temperature range of $0-100{ }^{\circ} \mathrm{C}$ for AMCD and $25-250{ }^{\circ} \mathrm{C}$ for TMX, AMCD, Poloxamer P- 407, mannitol and freeze-dried nanovesicles. The scan was recorded with a heating rate of $10{ }^{\circ} \mathrm{C} / \mathrm{min}$ in a nitrogen atmosphere, and data evaluated using the Star® Evaluation Software.

${ }^{1} \mathrm{H}-\mathrm{NMR}$ and ${ }^{13} \mathrm{C}-\mathrm{NMR}$ of AMCD and $\beta \mathrm{CD}$ were recorded using $500 \mathrm{mHz}$ Agilent NMR spectrometer in DMSO-D . The molecular weight of AMCD was recorded using MALDI-ToF mass spectrometer (Kratos/Shimadzu, AximaCFR). Elemental analysis of AMCD was performed using 2400 Series II CHNS/O elemental analysis system.

X-ray powder diffraction (XRPD) of TMX, physical mixture (TMX, AMCD, Poloxamer P- 407 and Mannitol) and freeze-dried nanovesicles were analyzed. X-ray diffractograms were recorded using X-Ray Diffractometer (Rigaku,

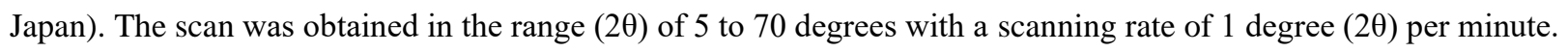

\section{Preparation of tamoxifen citrate (TMX) loaded AMCD nanovesicles}

Blank AMCD nanovesicles were prepared by modified ethanol injection method. Briefly, AMCD was dissolved in ethanol, and the solution was injected in an aqueous solution containing $0.5 \%$ w/v Kolliphor P407 at $60{ }^{\circ} \mathrm{C}$ rapidly. The dispersion was stirred at $60{ }^{\circ} \mathrm{C}$ to evaporate the ethanol and get the blank nanovesicles. To prepare TMX loaded Nanovesicles, TMX and AMCD both were dissolved in ethanol and the rest of the method was similar as of the blank nanovesicles. Physical stability of the prepared nanovesicles was studied at room temperature and at $2-8{ }^{\circ} \mathrm{C}$. Instability would be defined as any precipitation, drug crystallization, or turbidity. 


\section{Molecular modeling studies of TMX and AMCD interaction}

Structure collection: TMX structure was drawn and optimized using Ligprep module. Finally, the geometry optimization was carried out using the OPLS2005 force field, and structure of AMCD was generated by manually attaching C12 alkyl chains to the $\beta C D$ backbone. The geometry of AMCD structure was optimized OPLS2005 force field in Macro model suite (version 11.1, Schrödinger).

Molecular Docking: The Glide module was used for generating AMCD inclusion complexes. The grid was generated using the Glide Grid Generation panel in Glide. For generating AMCD binary supramolecular inclusion complex, TMX was docked with standard precision (SP) mode on AMCD (29).

MD simulation studies: Stability of AMCD: TMX complex was studied via MD simulation performed on the Desmond module (version 11.1, Schrödinger). The inclusion complex of AMCD-TMX was immersed in simulation box (orthorhombic $10 \AA$ A) with TIP4P explicit water molecules. The system was minimized and subjected to $10 \mathrm{~ns}$ MD simulation at $300 \mathrm{~K}$ temperature and 1.013 bar pressure with default settings. Generated MD trajectory was analyzed by event analysis tool.

\section{Physicochemical Characterization of nano-vesicles:}

\section{Particle size and Zeta Potential determination:}

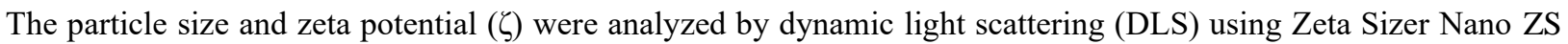
(Malvern Instrument Ltd., UK). Measurements were made at $25^{\circ} \mathrm{C}$ with a fixed angle of $137^{\circ}$ in a dilution of 1:10 using Milli-Q water.

\section{Determination of morphology of nanovesicles}

TEM analysis was employed to evaluate the shape and size of the nanovesicles. $10 \mu 1$ of the sample was placed on a grid and coated with uranyl acetate. After drying, the TEM image was recorded on TEM with accelerating voltage of $5 \mathrm{KV}$ on Phillips instrument.

AFM analysis was used to confirm the shape of nanovesicles. AFM images were acquired in the air under ambient conditions using a Bruker Multimode 8 Scanning Probe Microscope (Digital Instruments, Santa Barbara, CA, USA) operated on Peak Force QNM mode. $10 \mu \mathrm{l}$ of the nanovesicle suspension was placed on a freshly cleaved mica sheet $(1.5 \mathrm{~cm} \times 1.5 \mathrm{~cm}$; G250-2 Mica sheets 1" $\times 1$ " $\times 0.006$ "; Agar Scientific Ltd., Essex, UK) and air-dried for $\sim 1 \mathrm{hr}$. The AFM measurements were obtained using ScanAsyst-air probes (Bruker) with V-shaped silicon nitride cantilevers with spring constants in the range of $0.25-0.4 \mathrm{~N} \mathrm{~m}^{-1}$. AFM scans were acquired at a resolution of $512 \times 512$ pixels at a scan rate of $1 \mathrm{~Hz}$ and produced topographic images of the samples in which the brightness of features increases as a function of height. (30). AFM images were collected from random spot surface sampling.

The SANS measurements were performed on SANS instrument operating at Dhruva reactor, Bhabha Atomic Research Centre (BARC), Mumbai, India. The incident neutron of a wavelength of $5.2 \mathrm{~A}^{\circ}$ with approximately $15 \%$ wavelength resolution $(\Delta \lambda / \lambda)$. Linear position sensitive detector (angular range $0.5-15^{\circ}$ ) was used to impart Q-range of 0.018 and $0.32 \mathrm{~A}^{\circ-1}$. All the sample measurements were carried out at $37^{\circ} \mathrm{C}(31)$. 


\section{Encapsulation efficiency (\% EE)}

The percent encapsulation efficiency of TMX was calculated after separating unentrapped and entrapped TMX from the Nanovesicles using Nanosep ${ }^{\circledR}$ centrifugal device having Mol. Wt. The cut off of 30 KD. Briefly, Nanovesicle suspension was centrifuged at 15,000 rpm for $10 \mathrm{~min}$. The filter was washed thrice with Phosphate buffer saline (32). After three filtrations and centrifugation cycles, filtrate was analyzed using High Performance Liquid Chromatography (HPLC) using Waters C- 18 columns $\left(3 \mu \mathrm{m}, 4.6 \times 250 \mathrm{~mm}, 100 \mathrm{~A}^{\circ}\right)$ as a stationary phase and $1 \%(\mathrm{v} / \mathrm{v})$ triethanolamine in deionized distilled water, which was added to acetonitrile at a ratio of 50:50 (v/v) and pH adjusted to 3 using $0.1 \mathrm{~N}$ $\mathrm{HCl}$ as a mobile phase at a flow rate of $1 \mathrm{~mL} / \mathrm{min}$. TMX was detected at $\lambda_{\max } 275 \mathrm{~nm}$ (Linearity $\mathrm{r}^{2}=0.999$, Repeatability CV: $0.184 \%$, Specificity confirmed)(33).

\section{In Vitro Drug Release}

In vitro release of TMX from nanovesicles was performed using dialysis method. The nanovesicle suspension was placed in a dialysis membrane with 12,000 - 14,000 Dalton cut-off. Dialysis bag was placed in PBS buffer solutions. Two different $\mathrm{pH}$ buffers were used as release media; $\mathrm{pH} 7.4$ (plasma $\mathrm{pH}$ ) and $\mathrm{pH} 6.5$ (intertumoral $\mathrm{pH}$ ) to study the effect of $\mathrm{pH}$ on TMX release form nanovesicles. The study was carried out at $37{ }^{\circ} \mathrm{C}$, and the release medium was stirred at $100 \mathrm{rpm}$. Samples were collected at predetermined time points, and the amount of TMX released was determined using the HPLC described elsewhere. At each time point, the sample volume was replaced with fresh release medium pre-equilibrated at $37^{\circ} \mathrm{C}$, maintaining sink conditions during release studies $(32,34)$.

\section{In vitro and in vivo evaluation of Nanovesicles}

\section{In vitro Hemolysis using isolated human red blood cells}

Hemolysis study was performed using the method reported previously (14). Briefly, erythrocytes were harvested from heparinized human (Human blood collected from the healthy volunteer after their consent by expert pathologist in a pathology lab) by centrifugation. The supernatant plasma was discarded, and the sedimented erythrocyte cake washed thrice with PBS (pH 7.4). After the final wash, erythrocytes were resuspended in saline. Thereafter, $1.8 \mathrm{ml}$ of the erythrocyte suspension was incubated with $0.2 \mathrm{ml}$ of test samples (10 and $20 \mathrm{mM}$ solution of $\beta C D$ and AMCD) at $37^{\circ} \mathrm{C}$ for $30 \mathrm{~min}$ in a shaker and then centrifuged at $2,800 \mathrm{rpm}$ for $5 \mathrm{~min}$. The supernatant was analyzed for hemoglobin content at $543 \mathrm{~nm}$ spectrophotometrically (10). PBS (pH 7.4) was used as the negative control with $0 \%$ hemolysis, and distilled water was used as the positive control with $100 \%$ hemolysis. The percent hemolysis was calculated using Eq. $1(35)$.

$\%$ Hemolysis $=\frac{(U V \text { absorbance of sample treated with } R B C)}{(\text { UV absorbance of sample treated with distilled water })} \times 100$

\section{Comet Assay}

The comet assay was performed on HDMEC cells obtained from PromoCell GmbH to assess the potential genotoxicity of the synthesized AMCD. An alkaline comet assay was performed according to the directions provided by the manufacturer (comet Assay; Trevigen, Gaithersburg, MD(1), USA) (36,37). HDMEC cells were seeded into six-well 
plates at a density of $5 \times 10^{3}$ cells $/ \mathrm{cm}^{2}$ and allowed to grow for 24 hours. Cells were incubated with 20 and $200 \mu \mathrm{g} / \mathrm{ml}$ of AMCD for $24 \mathrm{hrs}$. The tail moment and olive moment were calculated (50 determination for each sample) and used as a measure of the primary DNA damage. Untreated cells and cells exposed for $20 \mathrm{~min}$ to $\mathrm{H}_{2} \mathrm{O}_{2}(200 \mu \mathrm{M})$ were used as negative control positive control, respectively.

Tail Moment $=$ Tail length $\times \%$ DNA in the tail

Olive Moment $=($ Centre of the mass of tail-Centre of the mass of head $) \times \%$ DNA in the tail

\section{In vitro cell cytotoxicity studies}

In vitro, cytotoxicity was carried out using the protocol described by $\mathrm{T}$. Wongpinyochit et al. (38). Briefly, the human breast cancer cell line MCF-7 was purchased from ATCC (Manassas, VA, U.S.A.). Cells were cultured in complete DMEM high glucose glutaMAX ${ }^{\mathrm{TM}}$ (4.5 g glucose, 10\% v/v FBS, $1 \%$ penicillin-streptomycin, $10 \mu \mathrm{g} / \mathrm{mL}$ insulin), grown at $37{ }^{\circ} \mathrm{C}$ in a humidified $5 \% \mathrm{CO}_{2}$ atmosphere and regularly subcultured every $2-3$ days. Cells were seeded in 96-well plates at a density of $2 \times 10^{4}$ cells $/ \mathrm{cm}^{2}$ and allowed to adhere overnight. Next, TMX stock solution in DMSO, blank AMCD nanovesicles and TMX loaded AMCD nanovesicle were filter sterilized and cells were treated using varying concentrations (0-250 $\mu \mathrm{g} / \mathrm{ml}$ ) of (a) TMX solution, (b) Blank AMCD nanovesicles, or (c) TMX loaded AMCD nanovesicles. After a 72-h incubation period, cell viability was determined using a 3-(4,5-dimethylthiazol-2-yl)-2,5diphenyltetrazolium bromide (MTT) assay. MTT was prepared at $5 \mathrm{mg} / \mathrm{mL}$ in PBS, and $20 \mu \mathrm{L}$ was added to each well followed by a $5 \mathrm{~h}$ incubation at $37^{\circ} \mathrm{C}$ in $5 \% \mathrm{CO}_{2}$. Further, $100 \mu \mathrm{L}$ of DMSO was added to dissolve the formazan product, and absorbance was measured at $570 \mathrm{~nm}$. Untreated control cells represented $100 \%$ cell viability, and the half maximal inhibitory concentration $\left(\mathrm{IC}_{50}\right)$ was calculated for the treatment groups.

\section{In vitro cell uptake studies}

Fluorescein loaded AMCD nanovesicles (FNV) were prepared and their uptake by MCF-7 cells was studied by flow cytometry and confocal microscopy.

For cell uptake studies, the cells were cultured using phenol red free complete culture medium. The cells were washed thrice with PBS and the culture medium was replaced with either (i) control DMEM or (ii) DMEM supplemented with equivalent $10 \mu \mathrm{g} / \mathrm{ml}$ of fluorescein as freely diffusible fluorescein and FNV. Cells were incubated for $1 \mathrm{~h}$. The incubation was arrested by placing the cells on ice, removing all the medium and washing with ice-cold PBS three times. For flow cytometry, live cells were trypsinized and harvested into 5-ml Falcon tubes and for confocal microscopy, cells were used as it is.

Data were collected using a BD FACSCanto ${ }^{\mathrm{TM}}$ flow cytometry system using BD FACSDiva software v6.3.1 (Becton Dickinson, San Jose, CA). A minimum of $>9000$ events was recorded within the gate, which was set and verified for the live singlets. FITC filter $(530 / 30 \mathrm{~nm}$ ) was used to measure the geometric mean fluorescence. FlowJo v10.1 (Tree Star, San Carlos, CA) was used for data analysis. 
Confocal imaging was acquired using live cells using a Leica TCS-SP5 confocal laser scanning microscope (Leica Microsystems GmbH, Wetzlar, Germany). Single confocal sections were acquired at an airy disc of 1. Image analysis was performed using ImageJ v1.51k 1.

Studies were also carried out at two temperatures, i.e. $37{ }^{\circ} \mathrm{C}$ and $4{ }^{\circ} \mathrm{C}$ to see if the energy-dependent uptake mechanisms are involved in the uptake of AMCD nanovesicles by MCF-7. Further, to study the uptake mechanism, cells were incubated with various endocytosis inhibitors for $1 \mathrm{~h}$. Chlorpromazine $(20 \mu \mathrm{M})$ was used clathrin-dependent endocytosis inhibitor. Methyl- $\beta$-cyclodextrin $(\mathrm{m} \beta \mathrm{CD}-5 \mathrm{mM})$ and genistein $(50 \mu \mathrm{M})$ were used to inhibit caveolaedependent endocytosis. Following a $1 \mathrm{~h}$ pre-treatment with each respective inhibitor, cells were thoroughly washed and incubated with FNV for 30 mins and analyzed using flow cytometry as mentioned above (39-41).

\section{Acute Toxicity studies}

The $\mathrm{LD}_{50}$ value of AMCD was investigated in Swiss albino mice (Female, 3 months, 20-25 gms). The study was planned after the animal ethics committee approval (Protocol no: ICT/IAEC/2017/P32). Five mice were used per group, and a single IV dose of 50,300, and 2,000 mg/kg of AMCD and saline as control were injected via the tail vein. Mice were observed for 14 days, and the number of animals surviving in each group was recorded. Blood plasma/serum analysis and histopathology of vital organs were performed after 14 days to look for any abnormalities and signs of toxicity.

\section{Pharmacokinetic studies}

Pharmacokinetic studies were performed on Male Wistar rat after obtaining Animal Ethics Committee Approval (Protocol approval no. MVC/IAEC/23/2016). The rats weighing 220-250 gm were divided into 2 different groups consisting of 6 animals each. Group I received TMX solution in normal saline containing 1\% ethanol and Group II received TMX loaded AMCD nanovesicles, at a dose equivalent to $5 \mathrm{mg} / \mathrm{kg}$ of TMX via the tail vein (42). About 400 $\mu 1$ of blood was collected via retro-orbital bleeding at suitable time points in the heparinized blood collection tube. Samples were centrifuged at $5000 \times \mathrm{g}$ to separate plasma. Plasma samples were carefully separated and stored at $4{ }^{\circ} \mathrm{C}$ until analyzed using HPLC for TMX content using etravirine as an internal standard. SALLE (salting out assisted liquid-liquid extraction) method was used for extraction of TMX from plasma. Chromatographic conditions were the same as described earlier in 2.4.3.

\section{Statistical Analyses}

Statistical analysis was performed using GraphPad Prism software (version 6.01) wherever necessary. Haemolysis data were analyzed using one-way analysis of variance (ANOVA) followed by Tukey's multiple comparisons test. Data of cytotoxicity studies and comet assay was analyzed by two-way analysis of variance (ANOVA) followed by Sidak's multiple comparisons test. Results were considered statistically significant at $\mathrm{p}<0.05$. 


\section{RESULTS}

\section{Synthesis and characterization of AMCD}

$\beta C D$ was converted to AMCD via nucleophilic substitution reaction. Lauroyl chloride was reacted with $\beta C D$ in alkaline conditions, and Lauroyl ester of $\beta \mathrm{CD}$ was formed with $\mathrm{HCl}$ as a by-product which was neutralized by an excess of Triethylamine in a reaction mixture. The degree of esterification of $\beta C D$ was proportional to moles of Lauroyl chloride reacted with 1 mole of $\beta C D$. In the present study, 15 moles of Lauroyl Chloride were reacted with 1 mole of $\beta C D$ to achieve partial random esterification of $\beta C D$. Pale yellow product (yield $=62 \%$ ) was obtained. Figure Supplementary figure 1(A) shows the FTIR spectra of AMCD showing a characteristic peak at $1743.65 \mathrm{~cm}^{-1}$ corresponding to carbonyl $(\mathrm{C}=\mathrm{O})$ stretching of ester suggesting the formation of Lauroyl ester of $\beta \mathrm{CD}$, wide absorption band at 3525 and $3332 \mathrm{~cm}^{-1}$ corresponding to $-\mathrm{OH}$ stretching of $\beta \mathrm{CD}$, strong peaks at 2854 and $2924 \mathrm{~cm}^{-1}$ and variable peaks in region $1350-1480 \mathrm{~cm}^{-1}$ assigned to $\mathrm{C}-\mathrm{H}$ stretching and bending vibrations of $\mathrm{C}-\mathrm{H}$ in alkyl chains respectively suggesting the formation of Lauroyl ester of $\beta C D$. Similar results were reported by Memisoglu et al. for hexanoyl ester of $\beta C D(43)$.

Further, DSC thermogram of AMCD represented in Supplementary figure 1 (B) showed a small endothermic melting peak at $54.68{ }^{\circ} \mathrm{C}$ with no other peaks till $300{ }^{\circ} \mathrm{C}$ indicating no sign of degradation.

MALDI-TOF analysis of AMCD using dithranol as a matrix substance showed a group of signals separated by mass unit equivalent to that of laurate chain. Results suggest the presence of polydisperse AMCD molecule with varying degree of substitution of 9-15 Laurate units to native $\beta C D$ with a molecular range of 2,799.81 - 3,884.50 $[\mathrm{M}+\mathrm{Na}]^{+}$. Average Degree of substitution from MALDI-TOF results is considered to be $12 \pm 3$, suggesting 12 hydroxyl groups out of 21 hydroxyl groups of $\beta C D$ was substituted with Laurate chain and average Mol. Wt. of AMCD was found to be $3322.3 \mathrm{~g} / \mathrm{mol}$. MALDI-TOF spectra of AMCD is shown in Supplementary figure 1 (C).

Elemental analysis of AMCD was performed. The results showed that the compound has an average of $66.905 \pm 0.035$ $\%$ Carbon and $10.125 \pm 0.134 \%$ Hydrogen. As seen in Supplementary figure 1(D) there is a linear increase in calculated $\log \%$ carbon and $\log \%$ hydrogen with an increase in log Ds (Ds in AMCD is a number of lauroyl chain attached to a single $\beta C D$ molecule). Thus, by extrapolating value of $\log \% \mathrm{C}\left(\log _{10} 66.905=1.855\right)$ and $\log \% \mathrm{H}\left(\log _{10}\right.$ $10.125=1.005) \log$ Ds of 1.08 and 1.096 respectively are obtained, which are equivalent to Ds of 12.021 and 12.473. The calculated results also support the finding of MALDI-TOF, which gave average Ds as 12 .

${ }^{1} \mathrm{H}$ NMR and ${ }^{13} \mathrm{C}$ NMR of AMCD were recorded in $\mathrm{CDCl}_{3}$ at ambient temperature and peaks were assigned assisted by HSQC spectra (Supplementary figure 2, 3 and 4). As seen in ${ }^{1} \mathrm{H}$ - NMR of AMCD, there is a downfield shift in $\mathrm{H}_{2}$, $\mathrm{H}_{3}$, and $\mathrm{H}_{6}$ due to the attachment of Lauric acid chains on all three hydroxyl groups (2-OH, 3-OH, and 6-OH) of native $\beta C D$. Amongst the three, $6-\mathrm{OH}$ is highly reactive, and thus all the 6-OH have been substituted and hence the 6-OH peak in ${ }^{1} \mathrm{H}-\mathrm{NMR}$ is missing, whereas smaller peaks of $2-\mathrm{OH}$ and $3-\mathrm{OH}$ at $\delta$ ppm 5.45 and 5.28 are retained which illustrate some of the 2-OH and 3-OH of native $\beta C D$ are unsubstituted. Due to the substitution of Lauric acid chain on 6-OH, two hydrogen atoms ( $\mathrm{H} 6 \mathrm{a}$ and $\mathrm{H} 6 \mathrm{~b}$ ) at $\mathrm{C} 6$ gave two distinct signals at 4.5 and $4.12 \delta$ ppm respectively which 
otherwise gives a peak at $3.64 \delta \mathrm{ppm}$ in native $\beta \mathrm{CD}$. Supplementary figure $2,{ }^{13} \mathrm{C}$ NMR spectra of AMCD shows a peak at $173.22 \delta \mathrm{ppm}$ corresponding to carbonyl carbon suggesting the formation of the ester bond. Additional peaks at $14.26,25.04,29.81$ and $34.11 \delta \mathrm{ppm}$ due to the lauric acid chain suggests the successful substitution of lauric acid chain on native $\beta C D$.

\section{Preparation and optimization of self-assembling nanovesicles}

Synthesized AMCD has the capability of self-assembling to form a nanovesicles in an aqueous medium. At first, no surfactant was used in the preparation of nanovesicles. The nanovesicles which were prepared without any surfactant gave a particle size of $256.3 \pm 11.2 \mathrm{~nm}$, but they were stable for only 2 days at R.T. and for 5 days at $2-8{ }^{\circ} \mathrm{C}$. Hence, different stabilizers were investigated in order to increase the stability of nanovesicles. Different stabilizer and their different concentrations were used to optimize nanovesicles are depicted in table 1.

Kolliphor P407 was very effective than Tween 80 and TPGS (d- $\alpha$-Tocopheryl polyethylene glycol 1000 succinate) in reducing the particle size as well as in stabilizing the nanovesicles which are formed by self-assembling of AMCD. Polymeric stabilizers are more effective in stabilizing the nanovesicles than the surfactant stabilizers. Poloxamer P407 helped to achieve the particle size of nanovesicles $<150 \mathrm{~nm}$ with very narrow PDI and a very good physical stability, hence $0.5 \%$ w/v of poloxamer P407 was selected for final formulation.

\section{Molecular modeling studies of TMX and AMCD interaction}

In-silico molecular docking and MD simulation studies are very helpful in understanding the molecular interaction involved during the complex formation and the stability of the complex. In the present study, when TMX was docked on AMCD, the stable complex was formed as seen in figure 2(A) and 2(B). One of the benzene rings of (1,2-Diphenyl1-butenyl) phenoxy side chain of TMX enters the cavity of AMCD through the secondary rim. The complex is stabilized through hydrogen bond between the nitrogen of $3^{\circ}$ amine in TMX and 2-OH group of glucopyranose of AMCD and several aromatic hydrogen bonds between phenyl groups of TMX and AMCD. The binding efficiency indicated by the glide docking score for the TMX and AMCD was found to be $-5.722 \mathrm{kcal} / \mathrm{mol}$. The stability of the complex in water was assessed by running an MD simulation of $10 \mathrm{~ns}$. MD simulation trajectory was analyzed for RMSD of AMCD, RMSD for TMX and RMSD of TMX with respect to AMCD which are presented in figure 2(C). Lower RMSD of TMX with respect to AMCD, when compared to RMSD of AMCD, represents the TMX is remain associated with AMCD and not getting diffused out of the complex suggesting the stability of the complex. RMSD of TMX is not significant, which suggests there are no conformational changes in TMX throughout the simulation period. Hydrogen bond analysis was also performed which suggested that there is at least 1 hydrogen bond present between TMX and AMCD (figure 2D) throughout the period which is stabilizing the complex with several other aromatic hydrogen bonds. 


\section{Physicochemical Characterization of nanovesicles}

\section{Evaluation of particle size, Zeta potential, and encapsulation efficiency}

The particle size of blank self-assembled nanovesicle was found to be in the range of $96.12 \pm 8.09 \mathrm{~nm}$ with PDI < 0.1 and that of optimized TMX loaded nanovesicles are in the range of $112.40 \pm 2.99$ with PDI $<0.2$. Zeta $(\zeta)$ potential of both blank and drug-loaded nanovesicles was $-10.65 \pm 0.53 \mathrm{mV}$ and $-11.56 \pm 0.36 \mathrm{mV}$ respectively. The encapsulation efficiency of optimized formulation was found to be $94.02 \pm 3.49 \%$.

\section{Morphology of nanovesicles}

TEM images of blank nanovesicles, as seen in figure 3 (A) showed a perfectly spherical nanovesicle size of $\sim 100 \mathrm{~nm}$. TEM of TMX loaded nano-vesicles in figure 3 (B) showed a slight increase in particle size due to drug loading.

AFM images of TMX-loaded nanovesicles in figure 3 (C) confirms the spherical shape of nanovesicles. Nanovesicles have a smooth surface with a particle size of around $<200 \mathrm{~nm}$. The particle size of nanovesicles is little larger in AFM which can be attributed to the flattening or collapsing of nanovesicle on the grid surface as an experiment is conducted in air.

SANS data and corresponding best-fit curve using spherical shell model for AMCD nanovesicle are shown in figure 4 (A) $(31,37,44)$. Deuterated water was used as a media to provide good contrast between the AMCD and the dispersion medium. Scattering curve showed a typical scattering profile exhibited by vesicular systems and absence of Braggs peaks confirm the unilamellarity of the vesicle formed by AMCD. The vesicle size after fitting the data in spherical core-shell model was found to be $\sim 100 \mathrm{~nm}$ with a shell thickness of about $7.2 \mathrm{~nm}$ and a polydispersity index of 0.3 .

The length of the AMCD molecule, when drawn in 3D, was found to be around $34.02 \mathrm{~A}^{\circ}$ as seen in figure 4 (B) and the approximate shell thickness of AMCD nanovesicle given by SANS data fitting was found to be around $7.2 \mathrm{~nm}$ which is approximately double the length of AMCD molecule, and supporting the theory of AMCD assembling in bilayer which in turn forms a nanovesicles. It is evident from the results of TEM, AFM, DLS, and SANS that AMCD is capable of self-assembling into nanovesicles of perfectly spherical shape and smooth surface which has a particle size of $\sim 100 \mathrm{~nm}$ with a narrow PDI.

\section{In vitro drug release studies}

AMCD nanovesicles, as seen in figure 5 showed a sustained release of TMX over a period of 48 hrs. Approximately $75 \%$ of the drug was released over $48 \mathrm{hrs}$ in both the dissolution media i.e. $\mathrm{pH} 6.5$ (Intratumoral $\mathrm{pH}$ ) and $\mathrm{pH} 7.4$ Phosphate buffer saline (blood plasma $\mathrm{pH}$ ). Initial burst release of TMX within $1 \mathrm{hr}$ from the system was found to be $16.9 \%$ and $19.6 \%$ for $\mathrm{pH} 6.5$ and $\mathrm{pH} 7.4$ respectively. Previously, Bilensoy et. al. reported $40 \%$ burst release of

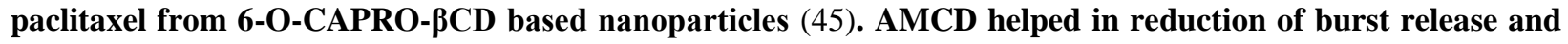
maintain the prolong release of drug for more than 24 hrs. Release data when fitted using different release models, drug release at both $\mathrm{pH}$ was found to fit Korsmeyer-Peppas model according to equation $\mathrm{F}=19.811 * \mathrm{t}^{\wedge} 0.361$ 
$\left(\mathrm{r}^{2}=0.9750\right)$ and $\mathrm{F}=22.376 * \mathrm{t}^{\wedge} 0.315\left(\mathrm{r}^{2}=0.9654\right)$ for $\mathrm{pH} 6.5$ and 7.4 respectively. $\mathrm{n}$ value of 0.361 and 0.315 , which was less than 0.5 in both the $\mathrm{pH}$ media indicated that TMX release from AMCD nanovesicles following a fickian diffusion $(46,47)$. Initial burst release can be associated with a drug bound to the surface rather than incorporated in the bilayer formed by AMCD which is released quickly while remaining drug is released slowly over a period of 48 hrs. There was no significant difference between the release at $\mathrm{pH} 6.5$ and $\mathrm{pH} 7.4$ and thus it can be assumed that TMX release will not be hampered due to the $\mathrm{pH}$ change in tumor environment and system will continue to release the drug as expected.

\section{Differential Scanning Calorimetry studies}

DSC thermogram of free TMX showed a sharp endothermic peak at $149.32{ }^{\circ} \mathrm{C}$ as seen in figure 6 (A), which corresponds to its melting point. This is in accordance with the previously reported results by Reddy et al. (42). Other excipients of nanovesicles such as AMCD, poloxamer P 407 and mannitol showed endothermic peaks at $54.68{ }^{\circ} \mathrm{C}$, $58.5^{\circ} \mathrm{C}$ and $168.34{ }^{\circ} \mathrm{C}$ respectively. In DSC thermogram of freeze dried TMX loaded nanovesicle, the peaks of excipients are retained whereas, the peak of TMX is missing suggesting that TMX is molecularly dispersed in AMCD bilayer and thus because of the amorphization of TMX, nanovesicle showed no characteristic melting peaks of TMX at around $149^{\circ} \mathrm{C}$.

\section{X-Ray Diffraction analysis}

The X-ray diffractogram of free TMX in figure 6 (B) showed several characteristics sharp peaks between at 11.72, 12.6, 13.94, 17.36, 17.92 and $21.54^{\circ}(2 \theta)$. Physical mixture retains peaks of TMX and other excipients whereas, peaks of TMX are either greatly diminished $\left(12.72,13.72,21.1^{\circ}\right)$ or entirely missing $\left(11.72,17.36,17.92^{\circ}\right)$ from the X-ray diffractogram of TMX loaded nanovesicles suggesting amorphization of TMX with entrapment of TMX within the nanovesicle. Results of XRD studies substantiate the results of DSC studies that TMX is molecularly dispersed in AMCD bilayer in nanovesicles.

\section{In vitro and in vivo evaluation of Nanovesicles:}

\section{In vitro Hemolysis study}

Starting material of AMCD i.e. $\beta C D$ is well known for its hemolytic activity because of its ability to disrupt the cell membrane of RBC by extracting phospholipids and cholesterol from the cell membrane (48). Thus, it is of utmost importance to make sure the material if safe for parenteral administration. As seen in Supplementary figure 5 (A), $\beta C D$ showed shown $\sim 3.3 \pm 0.32 \%$ and $29.64 \pm 0.9 \%$ hemolysis at 10 and $20 \mathrm{mM}$ concentration respectively. Whereas, AMCD showed significantly lesser ( $<0.0001$ ) hemolysis of $0.74 \pm 0.07 \%$ and $0.672 \pm 0.11 \%$ at equivalent concentration There was no significant difference between the \% hemolysis in negative control and that of 10 and 20 $\mathrm{mM}$ concentration of AMCD, which suggest the AMCD could be safe for parenteral administration. The Hemolytic potential of AMCD might be lost due to the self-assembling of AMCD molecules to form nanovesicles whereas, $\beta C D$ which gets solubilized and could be damaging RBC cell membrane. 


\section{Comet Assay}

Comet assay was performed to assess the genotoxicity of the AMCD in HDMEC cells by exposing cells to two different concentrations of AMCD 20 and $200 \mu \mathrm{g} / \mathrm{ml}$. cells treated with $\mathrm{H}_{2} \mathrm{O}_{2}(200 \mathrm{nM})$ were used as a positive control. Treated cells were compared with untreated cells. Supplementary figure 5 (B) shows an image of HDMEC cell nuclei stained by SYBR ${ }^{\circ}$ Gold dye after electrophoresis to separate intact DNA from damaged fragments. Cells treated with $\mathrm{H}_{2} \mathrm{O}_{2}$ showed degradation of DNA and the fragment of the damaged DNA formed a tail similar to a comet whereas the untreated cells nuclei appeared to be perfectly spherical and no tail was observed in cells (49). AMCD treated cells at both the concentrations was comparable to untreated cells and did not show any damage to DNA with no tail being observed around the nuclei. Results were further clear when the tail and olive moment was calculated. Values of both tail and olive moment showed no significant difference between untreated cells and AMCD treated cells at both the concentrations whereas positive control showed significantly higher tail and olive moment as seen in Supplementary figure 5 (C). This implies that the synthesized AMCD showed no damaging effect on the DNA of cells.

\section{In vitro cell cytotoxicity studies}

In vitro cytotoxicity of freely diffusible TMX solution, blank AMCD nanovesicles, and TMX loaded AMCD nanovesicles were assessed in MCF-7 cells after incubating cell with increasing concentrations of TMX (0-250 $\mu \mathrm{g} / \mathrm{mL}$ ) for 72 hours. As shown in figure 7 the growth inhibitory effect of TMX was evident both in freely diffusible form and when encapsulated in AMCD nanovesicles. Blank AMCD did not show any significant cytotoxic effect ( $p>0.05$ ) when compared to control. This suggested that the AMCD formulation was highly biocompatible. $\mathrm{IC}_{50}$ was calculated by nonlinear regression curve fitting. $\mathrm{IC}_{50}$ of freely diffusible TMX solution was found to be $11.43 \pm 0.955$ $\mu \mathrm{g} / \mathrm{ml}$ and that of TMX loaded AMCD nanovesicles was $7.796 \pm 0.247 \mu \mathrm{g} / \mathrm{ml}$. TMX showed concentration-dependent growth inhibition. At concentrations $>20 \mu \mathrm{g} / \mathrm{ml}$ both freely diffusible TMX solution and TMX loaded AMCD nanovesicles showed no significant difference in $\%$ inhibition of growth, however, below $20 \mu \mathrm{g} / \mathrm{ml}$ the encapsulated TMX showed significantly enhanced growth inhibitory effects than the freely diffusible TMX solution. This can be explained by the fact that the TMX loaded in the nanovesicles would have been taken up by the cells and further, the slow release of TMX within the cells over the period of $72 \mathrm{~h}$ showed higher $\%$ inhibition at lower concentrations.

\section{In vitro cell uptake studies}

Cellular uptake of freely diffusible fluorescein and FNV was quantitatively measured using flow cytometry. As seen in figure $8(\mathrm{~A})$, there was a significant $(\mathrm{p}<0.05)$ increase in uptake of FNV than that of freely diffusible fluorescein. This suggests that the internalization of nanovesicles by the MCF-7 cells was prominent than the freely diffusible fluorescein and thus the cell-associated fluorescence was significantly enhanced for FNV as compared to freely diffusible fluorescein. Further, when cells were incubated at $37{ }^{\circ} \mathrm{C}$ and $4{ }^{\circ} \mathrm{C}$ to study the energy dependency of nanovesicle uptake, it suggested that the uptake of nanovesicles was significantly higher $(\mathrm{p}<0.001)$ at $37{ }^{\circ} \mathrm{C}$ as compared to at $4{ }^{\circ} \mathrm{C}$, whereas uptake of freely diffusible fluorescein was not significantly affected at $4{ }^{\circ} \mathrm{C}$. This indicates that cellular uptake of AMCD nanovesicles was through energy-dependent endocytosis. Pre-treatment of cells with caveolae-dependent cell uptake inhibitors i.e. genistein and $M \beta C D$, significantly affected the uptake of FNV 
by $\sim 15$ and $40 \%$ respectively as seen in figure 8 (B) whereas, chlorpromazine which is a clathrin-mediated endocytosis inhibitor showed no significant reduction in cell-associated fluorescence when compared to control, suggesting that clathrin-mediated endocytosis is minor uptake mechanism for AMCD nanovesicles and caveolae-dependent cell internalization pathway plays a major role in internalization of AMCD nanovesicles $(50,51)$.

Confocal imaging was performed to confirm that the nanovesicles were actually internalized in the cells and not just associated with the surface of a cell which could also give the false positive results in FACS analysis. MCF-7 cells were incubated with FNV for $3 \mathrm{hr}$ and cells were washed and imaged live. Figure 9 shows a confocal image of MCF7 cells in bright field and in the green channel. As it is clearly seen from the image, FNV is internalized in the cells and not just associated with the surface, thus confirming the results of FACS.

\section{Acute toxicity study}

An acute toxicity study was performed to assess the median lethal dose $\left(\mathrm{LD}_{50}\right)$ of $\mathrm{AMCD}$. An acute toxicity study was conducted by giving 3 doses of 50, 300 and $2000 \mathrm{mg} / \mathrm{kg}$ of AMCD to five mice and observing them for 14 days for mortality. Mice injected with all the doses of AMCD were alive after 14 days, suggesting $\mathrm{LD}_{50}$ of $\mathrm{AMCD}$ can be safely assumed to be $>2000 \mathrm{mg} / \mathrm{kg}$. Mice which were given AMCD (2000 mg/kg dose) were sacrificed after 14 days and histopathology of their vital organs showed no abnormalities or any other signs of any toxicity (Supplementary figure 6A). Blood hematology parameters of that animal were not significantly different than the control animals (Supplementary figure 6B). Similar results were observed with serum biochemistry which remained unchanged and no significant difference was seen in serum chemistry of control animals and animals which were given a dose of AMCD at $2000 \mathrm{mg} / \mathrm{kg}$ (Supplementary figure 6C). Acute toxicity studies demonstrated that AMCD was well tolerated in mice at doses as high as $2000 \mathrm{mg} / \mathrm{kg}$.

\section{Pharmacokinetics studies}

Mean plasma concertation of TMX vs time an after single bolus IV bolus injection of TMX solution and TNV is shown in figure 10. Data were analyzed using PKSolver 2.0. The best fit was achieved with two compartmental IV bolus model which was described by the following equation

$\mathrm{C}=\mathrm{D}^{*}(\mathrm{~K} 21-\alpha) /(\operatorname{Vd}(\beta-\alpha)) * \mathrm{e}^{-\alpha \mathrm{t}}+\mathrm{D}^{*}(\mathrm{~K} 21-\beta) /(\operatorname{Vd}(\beta-\alpha))^{*} \mathrm{e}^{-\beta t}$

where, $\alpha+\beta=\mathrm{K} 12+\mathrm{K} 21+\mathrm{K} 10, \alpha \cdot \beta=\mathrm{K} 21 . \mathrm{K} 10, \mathrm{C}$ is concentration, $\mathrm{D}$ is dose, Vd is apparent volume of distribution, K12 and K21 represents distribution rate constant from the central compartment to the peripheral compartment and from peripheral compartment to the central compartment respectively. K10 denotes rate constant associated with the elimination from the central compartment, $\alpha$ is rate constant associated with the distribution phase of the concentration-time curve, $\beta$ is rate constant associated with the terminal phase of the concentration-time profile and $t$ is time (52). The calculated pharmacokinetic parameters are presented in table 2.

TMX solution showed a rapid initial drop in plasma concentration as compared to TNV due to rapid distribution of TMX solution in tissues, followed by a slow elimination phase. Encapsulation of TMX and slow release from nanovesicles reduced the rapid decline in plasma concertation. The rate of both the phases i.e. distribution, as well as 
elimination phase, was reduced and $\mathrm{t}_{1 / 2}$ of both the phase was prolonged for TNV as compared to TMX solution. Clearance of TMX solution was faster as compared to TNV, thus an increase in AUC by approximate three folds was observed. The mean residence time of TNV was also extended to $33 \mathrm{~h}$ as compared to $22 \mathrm{~h}$ for TMX solution. These results clearly show the changes in pharmacokinetic parameters of TMX due to the encapsulation in nanovesicles. An increase in MRT ensures that nanovesicles are present in circulation for a longer period of time providing more opportunities to nanovesicle for entering tumor tissues through EPR effect and thus making therapy more targeting.

\section{DISCUSSION}

Synthesis of amphiphilic cyclodextrin via nucleophilic substitution reaction using acid chloride yielded randomly substituted AMCD. FTIR and NMR studies confirm the formation of the ester bond. NMR studies revealed that primarily all 7, 6-OH of $\beta C D$ was substituted as it is highly reactive and few 2-OH and 3-OH were also substituted. MALDI and micro-elemental analysis confirmed the synthesis of AMCD with an average mol wt. of $3322.3 \mathrm{~g} / \mathrm{mol}$ and average Ds of 12. AMCD was able to self-assemble to form a nanovesicles in aqueous media, however, due to low zeta potential the physical stability was not achieved. Kolliphor P407 being a polymeric stabilizer enhanced the physical stability of the nanovesicles, similar results were obtained by Lemos-Senna et. al. who studied the effect of different stabilizer on the stability of amphiphilic cyclodextrin nanospheres (20). Molecular docking and MD simulation gave fair idea about how AMCD and TMX will interact and the stability of the complex which was formed. Alkyl chains attached to the $\beta C D$ moiety extended the cavity of $\beta C D$ and increase the interaction of TMX with AMCD. Sherje et al. also reported formation of stable complex of Etodolac with HP $\beta C D$ with similar glide score and complex was stabilized by various hydrogen and aromatic bonds as in present case (53). This stable complex will help retaining TMX in nanovesicle and will overcome the precipitation of drug which is a common problem for liposomal formulations (54). Many authors have used SANS to study the bilayer thickness in liposomes $(37,55,56)$, here the same study was used to study the thickness of AMCD shell which combined with data from in-silico data helped to deduce the structure of AMCD nanovesicles. After establishing the morphology and stability of AMCD nanovesicles, they were evaluated for their potential as a drug carrier by encapsulating TMX. AMCD nanovesicles were able to encapsulate TMX with drug loading as high as $10 \% \mathrm{w} / \mathrm{w}$ and released them slowly over the period of $48 \mathrm{hrs.} \mathrm{DSC} \mathrm{and}$ XRD studies showed the reduction in characteristic crystalline nature of TMX after encapsulation in AMCD nanovesicles. A similar observation was made by Çirpanli et.al., and Bilensoy et.al., who studied the encapsulation of Camptothecin and Paclitaxel in amphiphilic cyclodextrin nanosphere respectively (45,57). Further, the safety of AMCD was established by in vitro hemolysis where it was found to exhibit significantly lower hemolytic potential as compared to the parent $\beta C D$. Literature suggests that increasing substitution on native $\beta C D$ leads to a reduction in the hemolytic potential (58). Current research for the first-time established genotoxicity for amphiphilic cyclodextrins, comet assay suggested AMCD is non-genotoxic even at very high concentrations. In vitro cytotoxicity studies showed that nanocarrier itself was not cytotoxic but enhanced the cytotoxicity of TMX at low concentrations. This can be attributed to the slow release of drug over the period of time and active uptake of nanocarrier by the cells as seen by cell uptake studies. Unal et.al., reported similar findings where the cytotoxic effect of Camptothecin was significantly improved by encapsulating it in amphiphilic CD nanocarrier (59). Encapsulation in TMX in the AMCD nanovesicles 
has greatly affected its pharmacokinetic parameters. Reduced elimination rate constant, clearance and increased elimination $\mathrm{t}_{1 / 2}$, AUC and mean residence time suggests longer retention of TMX in plasma when encapsulated in AMCD nanovesicles. Similar results were reported by Li et. al., where encapsulation of TMX in liposomes extended the retention of TMX in plasma with an increase in AUC as seen in pharmacokinetic profile analyzed using two compartmental model (60).

\section{CONCLUSION}

Through the findings of the present study, it can be concluded that one step synthesis for randomly alkylated amphiphilic cyclodextrin is successful. Synthesized AMCD can form nanovesicles which are also able to encapsulate and slowly release TMX. Further, the safety of the AMCD was established by in vitro hemolysis, comet assay and acute toxicity studies making it a viable nanocarrier system for parenteral delivery. Nanovesicles appeared to be actively endocytosed by cells increasing the cytotoxicity of the encapsulated agent at lower doses. The pharmacokinetic study pointed out that elimination of encapsulated agent can be slowed down and mean residence time of carrier can be extended, giving it more opportunity to be targeted to the tumor via EPR effect.

\section{ACKNOWLEDGMENT}

Authors are thankful to DST-INSPIRE for fellowship (DST/INSPIRE/120736) and travel assistant. Authors are also grateful to the British council and DST for Newton-Bhabha Ph.D. Placement program (DST/INSPIRE/NBHF/2015/24). The authors would like to thank F. Philipp Seib (University of Strathclyde) and John D. Totten (University of Strathclyde) for providing tissue culture training and assistance with the experimental design of cytotoxicity, flow cytomertry and endocytosis studies. Authors want to acknowledge Dr. V. K. Aswal for helping with SANS study. Authors would also like to acknowledge TIFR (Mumbai, India) for proving the XRD facility for characterization, the Institute of Chemical Technology, AICTE/NAFETIC for providing laboratory facilities, and the Strathclyde Institute of Pharmacy \& Biomedical Sciences (SIPBS) for necessary infrastructure and facilities.

\section{ABBREVIATIONS}

${ }^{13} \mathrm{C}$ NMR, carbon-13 nuclear magnetic resonance; ${ }^{1} \mathrm{H}$ NMR, proton nuclear magnetic resonance;

AFM, atomic force microscopy; AMCD, amphiphilic cyclodextrin; ATCC, American type culture collection; CD, Cyclodextrin; $\mathrm{CO}_{2}$, carbon dioxide; DCM, dichloromethane ; DLS, dynamic light scattering; DMEM, Dulbecco's modified eagle medium; DMF, N, N-dimethylformamide; DMSO, dimethyl sulfoxide; DMSO- $\mathrm{D}_{6}$, deuterated dimethyl sulfoxide; Ds, degree of substitution; DSC, differential scanning calorimetry; FBS, fetal bovine serum; FNV, fluorescein loaded AMCD nanovesicles; FTIR, fourier-transform infrared spectroscopy; HPLC, high performance liquid chromatography; HSQC, heteronuclear single quantum correlation; $\mathrm{IC}_{50}$, half maximal inhibitory concentration; IV, intravenous; $\mathrm{KBr}$, Potassium bromide; $\mathrm{LD}_{50}$, median lethal dose; MALDI-TOF, matrix assisted laser desorption/ionization-time-of-flight; MTT, [3-(4,5-dimethylthiazol-2-yl)-2,5-diphenyltetrazolium bromide]; M $\beta C D$, methyl ßeta cyclodextrin; PBS, Phosphate buffer saline; PES, polyether sulfone; PLGA, poly(lactic-co-glycolic acid); PM, physical mixture; R.T., room temperature; RBC, red blood cells; SANS, small-angle neutron scattering; 
SMEDDS, Self-micro emulsifying drug delivery system; TEA, triethylamine; TEM, transmission electron microscopy; TLC, thin layer chromatography; TMX, tamoxifen citrate; UV, ultraviolet; $\beta C D$, $\beta$ eta cyclodextrin

\section{AUTHOR CONTRIBUTIONS}

M.R.P. and P.R.V. conceived the study. M.R.P. manufactured and characterized AMCD nanovesicles as well as performed transmission microscopy and AFM studies. D.A.L. provided training for AFM and host for the majority of experiments at the University of Strathclyde. M.R.P. performed all molecular docking and MD simulation studies. M.R.P and P.R.V. interpreted all the results of in-silico studies. In vitro and in vivo experiments were conducted by M.R.P. M.R.P. performed all animal studies. All authors (M.P., D.A.L, and P.R.V.) designed research, discussed the results, and/or advised on the analysis. M.R.P. and P.R.V wrote the manuscript with support from all the authors.

\section{DECLARATION OF INTEREST}

The authors report no conflicts of interest. The authors alone are responsible for the content and writing of this article.

\section{REFERENCES}

1. De Jong WH, Borm PJA. Drug delivery and nanoparticles:applications and hazards. Int J Nanomedicine [Internet]. 2008 [cited 2019 Jun 23];3(2):133-49. Available from: http://www.ncbi.nlm.nih.gov/pubmed/18686775

2. Rahman Z, Charoo NA, Akhter S, Beg S, Reddy IK, Khan MA. Nanotechnology-based drug products. In: Nanoscale Fabrication, Optimization, Scale-Up and Biological Aspects of Pharmaceutical Nanotechnology [Internet]. Elsevier; 2018. p. 619-55. Available from: http://dx.doi.org/10.1016/B978-0-12-813629-4.000164

3. Ochekpe N, Olorunfemi P, Ngwuluka N. Nanotechnology and Drug Delivery Part 2: Nanostructures for Drug Delivery. Trop J Pharm Res [Internet]. 2009;8(3):275-87. Available from: http://www.ajol.info/index.php/tjpr/article/view/44547

4. Rana V, Sharma R. Recent Advances in Development of Nano Drug Delivery [Internet]. Applications of Targeted Nano Drugs and Delivery Systems. Elsevier Inc.; 2019. 93-131 p. Available from: http://dx.doi.org/10.1016/B978-0-12-814029-1.00005-3

5. Loftsson T, Hreinsdóttir D, Másson M. Evaluation of cyclodextrin solubilization of drugs. Int J Pharm [Internet]. 2005 Sep;302(1-2):18-28. Available from: https://linkinghub.elsevier.com/retrieve/pii/S0378517305004400

6. Tayade P, Vavia P. Inclusion complexes of Ketoprofen with $\beta$-cyclodextrins: Oral pharmacokinetics of Ketoprofen in human. Indian J Pharm Sci [Internet]. 2006;68(2):164. Available from: http://www.ijpsonline.com/text.asp?2006/68/2/164/25709

7. Loftsson T, Jarho P, Másson M, Järvinen T. Cyclodextrins in drug delivery. Expert Opin Drug Deliv [Internet]. 2005 Mar 12;2(2):335-51. Available from: https://linkinghub.elsevier.com/retrieve/pii/S0169409X98000519

8. Loftsson T, Brewster ME, Masson M. Role of Cyclodextrins in Improving Oral Drug Delivery. Am J Drug Deliv [Internet]. 2004;2(4):261-75. Available from: http://link.springer.com/10.2165/00137696-20040204000006

9. Fateminasab F, Bordbar AK, Shityakov S. Detailed chemical characterization and molecular modeling of serotonin inclusion complex with unmodified $\beta$-cyclodextrin. Heliyon [Internet]. 2019;5(4):e01405.

Available from: https://doi.org/10.1016/j.heliyon.2019.e01405 
10. Cavalli R, Trotta F, Tumiatti W. Cyclodextrin-based Nanosponges for Drug Delivery. J Incl Phenom Macrocycl Chem [Internet]. 2006 Mar 29;56(1-2):209-13. Available from: http://link.springer.com/10.1007/s10847-006-9085-2

11. Swaminathan S, Pastero L, Serpe L, Trotta F, Vavia P, Aquilano D, et al. Cyclodextrin-based nanosponges encapsulating camptothecin: physicochemical characterization, stability and cytotoxicity. Eur J Pharm Biopharm [Internet]. 2010 Mar [cited 2013 May 29];74(2):193-201. Available from: http://www.ncbi.nlm.nih.gov/pubmed/19900544

12. Ansari K a, Vavia PR, Trotta F, Cavalli R. Cyclodextrin-based nanosponges for delivery of resveratrol: in vitro characterisation, stability, cytotoxicity and permeation study. AAPS PharmSciTech [Internet]. 2011 Mar [cited 2013 Jun 22];12(1):279-86. Available from: http://www.pubmedcentral.nih.gov/articlerender.fcgi?artid=3066340\&tool=pmcentrez\&rendertype=abstract

13. Dora CP, Trotta F, Kushwah V, Devasari N, Singh C, Suresh S, et al. Potential of erlotinib cyclodextrin nanosponge complex to enhance solubility, dissolution rate, in vitro cytotoxicity and oral bioavailability. Carbohydr Polym [Internet]. 2016 Feb 10 [cited 2016 Feb 11];137:339-49. Available from: http://www.ncbi.nlm.nih.gov/pubmed/26686138

14. Torne S, Darandale S, Vavia P, Trotta F, Cavalli R. Cyclodextrin-based nanosponges: effective nanocarrier for tamoxifen delivery. Pharm Dev Technol [Internet]. 2013;18(3):619-25. Available from: http://www.ncbi.nlm.nih.gov/pubmed/22235935

15. Bilensoy E, Hincal a A. Recent advances and future directions in amphiphilic cyclodextrin nanoparticles. Expert Opin Drug Deliv [Internet]. 2009 Nov;6(11):1161-73. Available from: http://www.ncbi.nlm.nih.gov/pubmed/19705965

16. Jabbari A, Sadeghian H. Amphiphilic Cyclodextrins, Synthesis, Utilities and Application of Molecular Modeling in Their Design. Recent Adv Nov Drug Carr Syst. 2012;331-54.

17. Roux M, Perly B, Djedaïni-Pilard F. Self-assemblies of amphiphilic cyclodextrins. Eur Biophys J. 2007 Nov;36(8):861-7.

18. Zhang P, Chang-Chun L, Coleman AW, Parrot-Lopez H, Galons H. Formation of amphiphilic cyclodextrins via hydrophobic esterification at the secondary hydroxyl face. Tetrahedron Lett. 1991;32(24):2769-70.

19. Godínez LA, Lin J, Muñoz M, Coleman AW, Rubin S, Parikh A, et al. Multilayer Self-Assembly of Amphiphilic Cyclodextrin Hosts on Bare and Modified Gold Substrates: Controlling Aggregation via Surface Modification. Langmuir [Internet]. 1998 Jan;14(1):137-44. Available from: http://pubs.acs.org/doi/abs/10.1021/la970749w

20. Lemos-Senna E, Wouessidjewe D, Lesieur S, Puisieux F, Couarraze G, Duchêne D, et al. Evaluation of the hydrophobic drug loading characteristics in nanoprecipitated amphiphilic cyclodextrin nanospheres. Pharm Dev Technol. 1998 Jan 27;3(1):85-94.

21. Lemos-Senna E, Wouessidjewe D, Lesieur S, Duchêne D, Duchene D. Preparation of amphiphilic cyclodextrin nanospheres using the emulsification solvent evaporation method. Influence of the surfactant on preparation and hydrophobic drug loading. Int J Pharm. 1998 Aug 1;170(1):119-28.

22. Choisnard L, Gèze A, Putaux J-L, Wong Y-S, Wouessidjewe D. Nanoparticles of beta-cyclodextrin esters obtained by self-assembling of biotransesterified beta-cyclodextrins. Biomacromolecules [Internet]. 2006 Mar;7(2):515-20. Available from: http://www.ncbi.nlm.nih.gov/pubmed/16471924

23. Dayrit FM. Lauric acid is a medium-chain fatty acid, coconut oil is a medium-chain triglyceride. Philipp J Sci. 2014;143(2):157-66.

24. Szejtli J. Limits of cyclodextrin application in oral drug preparations. J Incl Phenom [Internet]. 1984;2(34):487-501. Available from: http://link.springer.com/10.1007/BF00662215

25. Maji R, Dey NS, Satapathy BS, Mukherjee B, Mondal S. Preparation and characterization of tamoxifen citrate loaded nanoparticles for breast cancer therapy. Int J Nanomedicine. 2015;9(1):3107-18.

26. Fontana G, Maniscalco L, Schillaci D, Cavallaro G, Giammona G. Solid Lipid Nanoparticles Containing Tamoxifen Characterization and In Vitro Antitumoral Activity. Drug Deliv [Internet]. 2005;12(6):385-92. 
Available from: http://www.tandfonline.com/doi/full/10.1080/10717540590968855

27. Monteagudo E, Gándola Y, González L, Bregni C, Carlucci a M. Development, characterization, and in vitro evaluation of tamoxifen microemulsions. J Drug Deliv [Internet]. 2012;2012:236713. Available from: http://www.pubmedcentral.nih.gov/articlerender.fcgi?artid=3261494\&tool=pmcentrez\&rendertype=abstract

28. Layek B, Mukherjee B. Tamoxifen citrate encapsulated sustained release liposomes: Preparation and evaluation of physicochemical properties. Sci Pharm [Internet]. 2010 [cited 2018 Jan 13];78(3):507-15. Available from: http://dx.doi.org/10.3797/scipharm.0911-11

29. Patel M, Hirlekar R, Mayank P, Rajashree H, Patel M, Hirlekar R. Multicomponent cyclodextrin system for improvement of solubility and dissolution rate of poorly water soluble drug. Asian J Pharm Sci [Internet]. 2019 Jan 13 [cited 2018 Apr 4];14(1):104-15. Available from: https://www.sciencedirect.com/science/article/pii/S1818087617307006?via\%3Dihub

30. Fernández-Luna VG, Mallinson D, Alexiou P, Khadra I, Mullen AB, Pelecanou M, et al. Isatin thiosemicarbazones promote honeycomb structure formation in spin-coated polymer films: concentration effect and release studies. RSC Adv [Internet]. 2017;7(21):12945-52. Available from: http://xlink.rsc.org/?DOI=C6RA28163J

31. Singla P, Singh O, Chabba S, Aswal VK, Mahajan RK. Sodium deoxycholate mediated enhanced solubilization and stability of hydrophobic drug Clozapine in pluronic micelles. Spectrochim Acta Part A Mol Biomol Spectrosc [Internet]. 2018 Feb;191:143-54. Available from: http://linkinghub.elsevier.com/retrieve/pii/S1386142517308144

32. Chen H, Gao J, Wang F, Liang W. Preparation, Characterization and Pharmacokinetics of LiposomesEncapsulated Cyclodextrins Inclusion Complexes for Hydrophobic Drugs. Drug Deliv [Internet]. 2007 [cited 2018 Jan 13];14(4):201-8. Available from: http://www.tandfonline.com/doi/full/10.1080/10717540601036880

33. Dehghani F, Farhadian N, Golmohammadzadeh S, Biriaee A, Ebrahimi M, Karimi M. Preparation, characterization and in-vivo evaluation of microemulsions containing tamoxifen citrate anti-cancer drug. Eur J Pharm Sci [Internet]. 2017;96:479-89. Available from: http://dx.doi.org/10.1016/j.ejps.2016.09.033

34. Pawar S, Vavia P. Glucosamine anchored cancer targeted nano-vesicular drug delivery system of doxorubicin. J Drug Target [Internet]. 2016 Jan 2 [cited 2017 Oct 21];24(1):68-79. Available from: https://www.tandfonline.com/doi/full/10.3109/1061186X.2015.1055572

35. Bilensoy E, Gürkaynak O, Doğan a L, Hincal a A. Safety and efficacy of amphiphilic beta-cyclodextrin nanoparticles for paclitaxel delivery. Int J Pharm [Internet]. 2008 Jan 22;347(1-2):163-70. Available from: http://www.ncbi.nlm.nih.gov/pubmed/17689901

36. Tabei Y, Sonoda A, Nakajima Y, Biju V, Makita Y, Yoshida Y, et al. Intracellular accumulation of indium ions released from nanoparticles induces oxidative stress, proinflammatory response and DNA damage. J Biochem. 2015;159(2):225-37.

37. Monpara J, Kanthou C, Tozer GM, Vavia PR. Rational design of cholesterol derivative for improved stability of paclitaxel cationic liposomes. Pharm Res [Internet]. 2018 Apr 8;35(4):90. Available from: http://link.springer.com/10.1007/s11095-018-2367-8

38. Wongpinyochit T, Uhlmann P, Urquhart AJ, Seib FP. PEGylated Silk Nanoparticles for Anticancer Drug Delivery. Biomacromolecules. 2015;16(11):3712-22.

39. Patel K, Doddapaneni R, Sekar V, Chowdhury N, Singh M. Combination Approach of YSA Peptide Anchored Docetaxel Stealth Liposomes with Oral Antifibrotic Agent for the Treatment of Lung Cancer. Mol Pharm. 2016;13(6):2049-58.

40. Ma DX, Shi NQ, Qi XR. Distinct transduction modes of arginine-rich cell-penetrating peptides for cargo delivery into tumor cells. Int J Pharm [Internet]. 2011;419(1-2):200-8. Available from: http://dx.doi.org/10.1016/j.ijpharm.2011.08.001

41. Kojic LD, Joshi B, Lajoie P, Le PU, Cox ME, Turbin DA, et al. Raft-dependent Endocytosis of Autocrine Motility Factor Is Phosphatidylinositol 3-Kinase-dependent in Breast Carcinoma Cells. J Biol Chem 
[Internet]. 2007 Oct 5;282(40):29305-13. Available from:

http://www.jbc.org/lookup/doi/10.1074/jbc.M704069200

42. Harivardhan Reddy L, Vivek K, Bakshi N, Murthy RSR. Tamoxifen Citrate Loaded Solid Lipid Nanoparticles (SLN ${ }^{\mathrm{TM}}$ ): Preparation, Characterization, In Vitro Drug Release, and Pharmacokinetic Evaluation. Pharm Dev Technol [Internet]. 2006 Jan 7;11(2):167-77. Available from:

http://www.tandfonline.com/doi/full/10.1080/10837450600561265

43. Memişoğlu E, Bochot A, Şen M, Charon D, Duchêne D, Hıncal AA. Amphiphilic $\beta$-Cyclodextrins Modified on the Primary Face: Synthesis, Characterization, and Evaluation of Their Potential as Novel Excipients in the Preparation of Nanocapsules. J Pharm Sci [Internet]. 2002 May 1;91(5):1214-24. Available from: http://linkinghub.elsevier.com/retrieve/pii/S0022354916309935

44. Chen S-H, Lin T-L. Colloidal Solutions. In 1987. p. 489-543.

45. Bilensoy E, Gürkaynak O, Ertan M, Şen M, Hıncal AA. Development of Nonsurfactant Cyclodextrin Nanoparticles Loaded With Anticancer Drug Paclitaxel. J Pharm Sci [Internet]. 2008 Apr;97(4):1519-29. Available from: https://linkinghub.elsevier.com/retrieve/pii/S0022354916325333

46. Dash S, Murthy PN, Nath L, Chowdhury P. Kinetic Modeling on Drug Release from Controlled Drug Delivery Systems. Acta Pol Pharm Res. 2010;67(3):217-23.

47. Karpinich NO, Tafani M, Rothman RJ, Russo MA, Farber JL. The course of etoposide-induced apoptosis from damage to DNA and p53 activation to mitochondrial release of cytochrome c. J Biol Chem. 2002;277(19):16547-52.

48. Quaglia F, Ostacolo L, Mazzaglia A, Villari V, Zaccaria D, Sciortino MT. The intracellular effects of nonionic amphiphilic cyclodextrin nanoparticles in the delivery of anticancer drugs. Biomaterials [Internet]. 2009 Jan [cited 2017 May 5];30(3):374-82. Available from: http://dx.doi.org/10.1016/j.biomaterials.2008.09.035

49. Olive PL, Banáth JP. The comet assay: A method to measure DNA damage in individual cells. Nat Protoc. 2006;1(1):23-9.

50. Cuong N Van, Li YL, Hsieh MF. Targeted delivery of doxorubicin to human breast cancers by folatedecorated star-shaped PEG-PCL micelle. J Mater Chem. 2012;22(3):1006-20.

51. Li YL, Van Cuong N, Hsieh MF. Endocytosis pathways of the folate tethered star-shaped PEG-PCL micelles in cancer cell lines. Polymers (Basel). 2014;6(3):634-50.

52. Sridhar, A; Jithan, A.V.; Malla Reddy V. Comparative Pharmacokinetics of Free and LiposomeEncapsulated Catechin after Intravenous and Intraperitoneal Administration. Int J Pharm Sci Nanotechnol. 2008;1(2):152-9.

53. Sherje AP, Kulkarni V, Murahari M, Nayak UY, Bhat P, Suvarna V, et al. Inclusion complexation of etodolac with hydroxypropyl-beta-cyclodextrin and auxiliary agents: Formulation characterization and molecular modeling studies. Mol Pharm [Internet]. 2017 Apr 3 [cited 2018 Jan 18];14(4):1231-42. Available from: http://pubs.acs.org/doi/10.1021/acs.molpharmaceut.6b01115

54. Olusanya T, Haj Ahmad R, Ibegbu D, Smith J, Elkordy A, Olusanya TOB, et al. Liposomal Drug Delivery Systems and Anticancer Drugs. Molecules [Internet]. 2018 Apr 14 [cited 2019 Jul 15];23(4):907. Available from: http://www.mdpi.com/1420-3049/23/4/907

55. Nieh M-P, Glinka CJ, Krueger S, Prosser RS, Katsaras J. SANS Study of the Structural Phases of Magnetically Alignable Lanthanide-Doped Phospholipid Mixtures. Langmuir [Internet]. 2001 May;17(9):2629-38. Available from: http://pubs.acs.org/doi/abs/10.1021/la001567w

56. Yue B, Huang C-YY, Nieh M-PP, Glinka CJ, Katsaras J. Highly stable phospholipid unilamellar vesicles from spontaneous vesiculation: A DLS and SANS study. J Phys Chem B [Internet]. 2005 Jan;109(1):60916. Available from: http://pubs.acs.org/doi/abs/10.1021/jp047510q

57. Çirpanli Y, Bilensoy E, Lale Doğan A, Çaliş S. Comparative evaluation of polymeric and amphiphilic cyclodextrin nanoparticles for effective camptothecin delivery. Eur J Pharm Biopharm [Internet]. 2009 Sep;73(1):82-9. Available from: http://www.ncbi.nlm.nih.gov/pubmed/19442723 
58. Jodál I, Nánási P, Szejtli J. Investigation of the Hemolytic Effect of the Cyclodextrin Derivatives. In: Proceedings of the Fourth International Symposium on Cyclodextrins. Dordrecht: Springer Netherlands; 1988. p. 421-5.

59. Ünal H, Öztürk N, Bilensoy E. Formulation development, stability and anticancer efficacy of core-shell cyclodextrin nanocapsules for oral chemotherapy with camptothecin. Beilstein J Org Chem [Internet]. 2015 Feb 4 [cited 2016 Feb 11];11(5 mL):204-12. Available from:

http://www.pubmedcentral.nih.gov/articlerender.fcgi?artid=4362320\&tool=pmcentrez\&rendertype=abstract

60. Li MH, Yu H, Wang TF, Chang ND, Zhang JQ, Du D, et al. Tamoxifen embedded in lipid bilayer improves the oncotarget of liposomal daunorubicin in vivo. J Mater Chem B. 2014;2(12):1619-25. 
Table caption

Table 1: Effect of different surfactant and their concentration on particle size and stability of nanovesicles.

Table 2: Pharmacokinetic parameters of TMX solution and TNV after single IV bolus of $5 \mathrm{mg} / \mathrm{kg}$ per rat.

Table 1.

\begin{tabular}{llllll}
\hline Stabilizer & concentration & $\begin{array}{l}\text { Particle size } \\
(\mathbf{n m})\end{array}$ & PDI & $\begin{array}{l}\text { Stability at } \\
\mathbf{R . ~ T}(\mathbf{d a y s})\end{array}$ & $\begin{array}{l}\text { Stability at } \\
\mathbf{2 - 8} \mathbf{C}^{\circ} \mathbf{C} \text { (days) }\end{array}$ \\
\hline No stabilizer & - & $256.3 \pm 11.2$ & $0.366 \pm 0.036$ & 2 & 5 \\
\hline \multirow{2}{*}{ Tween 80} & $0.25 \% \mathrm{w} / \mathrm{v}$ & $173.2 \pm 9.7$ & $0.293 \pm 0.047$ & 3 & 7 \\
\cline { 2 - 6 } & $0.5 \% \mathrm{w} / \mathrm{v}$ & $153.6 \pm 7.6$ & $0.264 \pm 0.037$ & 3 & 7 \\
\hline \multirow{2}{*}{ TPGS } & $0.25 \% \mathrm{w} / \mathrm{v}$ & $185.6 \pm 9.9$ & $0.225 \pm 0.054$ & 2 & 6 \\
\cline { 2 - 6 } & $0.5 \% \mathrm{w} / \mathrm{v}$ & $154.7 \pm 11$ & $0.263 \pm 0.063$ & 3 & 7 \\
\hline \multirow{2}{*}{ Kolliphor $\mathrm{P} 407$} & $0.25 \% \mathrm{w} / \mathrm{v}$ & $112.0 \pm 9.4$ & $0.149 \pm 0.026$ & 15 & $>3$ months \\
\cline { 2 - 6 } & $0.5 \% \mathrm{w} / \mathrm{v}$ & $102.9 \pm 7.7$ & $0.095 \pm 0.007$ & 20 & $>3$ months \\
\hline
\end{tabular}

Table 2

\begin{tabular}{llll}
\hline Parameter & Unit & TMX solution & TNV \\
\hline $\mathrm{k} 10$ & $1 / \mathrm{min}$ & 0.003164 & 0.00077 \\
$\mathrm{k} 12$ & $1 / \mathrm{min}$ & 0.060266 & 0.019385 \\
$\mathrm{k} 21$ & $1 / \mathrm{min}$ & 0.018592 & 0.036736 \\
t1/2Alpha & $\mathrm{min}$ & 8.52603 & 12.29216 \\
t1/2Beta & $\mathrm{min}$ & 958.0821 & 1381.804 \\
$\mathrm{C} 0$ & $\mu \mathrm{g} / \mathrm{ml}$ & 0.822446 & 0.73008 \\
$\mathrm{~V}$ & $(\mathrm{mg}) /(\mu \mathrm{g} / \mathrm{ml})$ & 1.519857 & 1.712141 \\
$\mathrm{CL}$ & $(\mathrm{mg}) /(\mu \mathrm{g} / \mathrm{ml}) / \mathrm{min}$ & 0.004808 & 0.001318 \\
V2 & $(\mathrm{mg}) /(\mu \mathrm{g} / \mathrm{ml})$ & 4.926661 & 0.903501 \\
CL2 & $(\mathrm{mg}) /(\mu \mathrm{g} / \mathrm{ml}) / \mathrm{min}$ & 0.091595 & 0.033191 \\
AUC $0-\mathrm{t}$ & $\mu \mathrm{g} / \mathrm{ml} * \mathrm{~min}$ & 171.0271 & 489.9296 \\
AUC $0-$ inf & $\mu \mathrm{g} / \mathrm{ml} * \mathrm{~min}$ & 259.9724 & 948.1578 \\
MRT & $\mathrm{min}$ & 1340.734 & 1984.033 \\
Vss & $\mathrm{mg} /(\mu \mathrm{g} / \mathrm{ml})$ & 6.446519 & 2.615642 \\
\hline
\end{tabular}




\section{Figure Caption}

Figure 1: Reaction scheme for the synthesis of AMCD. a) Dry DMF, triethylamine, $30{ }^{\circ} \mathrm{C}, 24 \mathrm{~h}$, under nitrogen environment.

Figure 2 (A) Top view of docked pose for TMX and AMCD (B) Side view of docked pose of TMX and AMCD showing hydrogen bonds formed between TMX and AMCD (C) RMSD calculation for trajectory of TMX and AMCD MD simulation (D) Hydrogen bond analysis between TMX and AMCD during MD simulation period.

Figure 3 (A) TEM image of Blank nano-vesicles (B) TEM image of TMX-loaded nano-vesicles (C) AFM height image (3D) of TMX-loaded Nanovesicles (image size $1 \times 1 \mu \mathrm{m}$ ) (D) AFM height image (2D) of TMX-loaded nanovesicle (image size $3 \times 3 \mu \mathrm{m}$ ) (E) cross-section of single nanovesicle showing a smooth spherical particle of 180 nm.

Figure 4 (A) SANS data of AMCD nanovesicles with a corresponding best fit curve using spherical core-shell model (B) 3D structure of AMCD molecule with molecular length measurement (C) Schematic representation of the proposed structure of self-assembled nanovesicle of AMCD showing the arrangement of AMCD molecules to form a bilayer of thickness $\sim 7.2 \mathrm{~nm}$.

Figure 5 The release profile of TMX from AMCD nanovesicles in $\mathrm{pH} 6.5$ and $\mathrm{pH} 7.4$ Phosphate buffer at $37{ }^{\circ} \mathrm{C}$ using the dialysis method. Data expressed as mean $\pm \mathrm{SD}, \mathrm{n}=3$.

Figure 6 (A) DSC thermogram of TMX, AMCD, Poloxamer P 407, Mannitol and freeze dried TNV (B) X-ray Diffractogram of TMX, Poloxamer p 407, Mannitol, AMCD, Physical mixture and freeze dried TNV.

Figure 7 Cell viability of blank AMCD nanovesicles, freely diffusible TMX solution, and TMX loaded AMCD nanovesicles against MCF-7 cell line after $72 \mathrm{~h}$ incubation. $* *$ signifies $\mathrm{p}<0.01$ and $* * * *$ signifies $\mathrm{p}<0.0001$. Data represent the mean \pm SD of 6 independent experiments.

Figure 8 cell uptake studies (A) cell-associated fluorescence after incubating cells with freely diffusible fluorescein and FNV at $37{ }^{\circ} \mathrm{C}$ and $4{ }^{\circ} \mathrm{C}$ (B) effect of endocytosis inhibitors on internalization of FNV in MCF-7 cells. Cells were pre-treated with Chlorpromazine, Genistein, and Methyl- $\beta$-CD for $1 \mathrm{~h}$ followed by washing and incubation with FNV for $1 \mathrm{~h}$ followed by flow cytometric analysis. * signifies $\mathrm{p}<0.05$ and $* * *$ signifies $\mathrm{p}<0.001$. Data represented as Mean $\pm \operatorname{SD}(n=4)$.

Figure 9 confocal images of MCF-7 cells incubated with FNV for $3 \mathrm{~h}$ and imaged live after washing (A) bright field image at 10X (B) Green channel image of the same area at 10X (C) composed image of bright field and green channel superimposed at $10 \mathrm{X}$.

Figure 10 Mean plasma concentration of TMX vs Time profile for TMX solution (closed square) and for TNV (closed triangle). Data represented as Mean $\pm \mathrm{SD}(\mathrm{n}=6)$. 
Figure 1

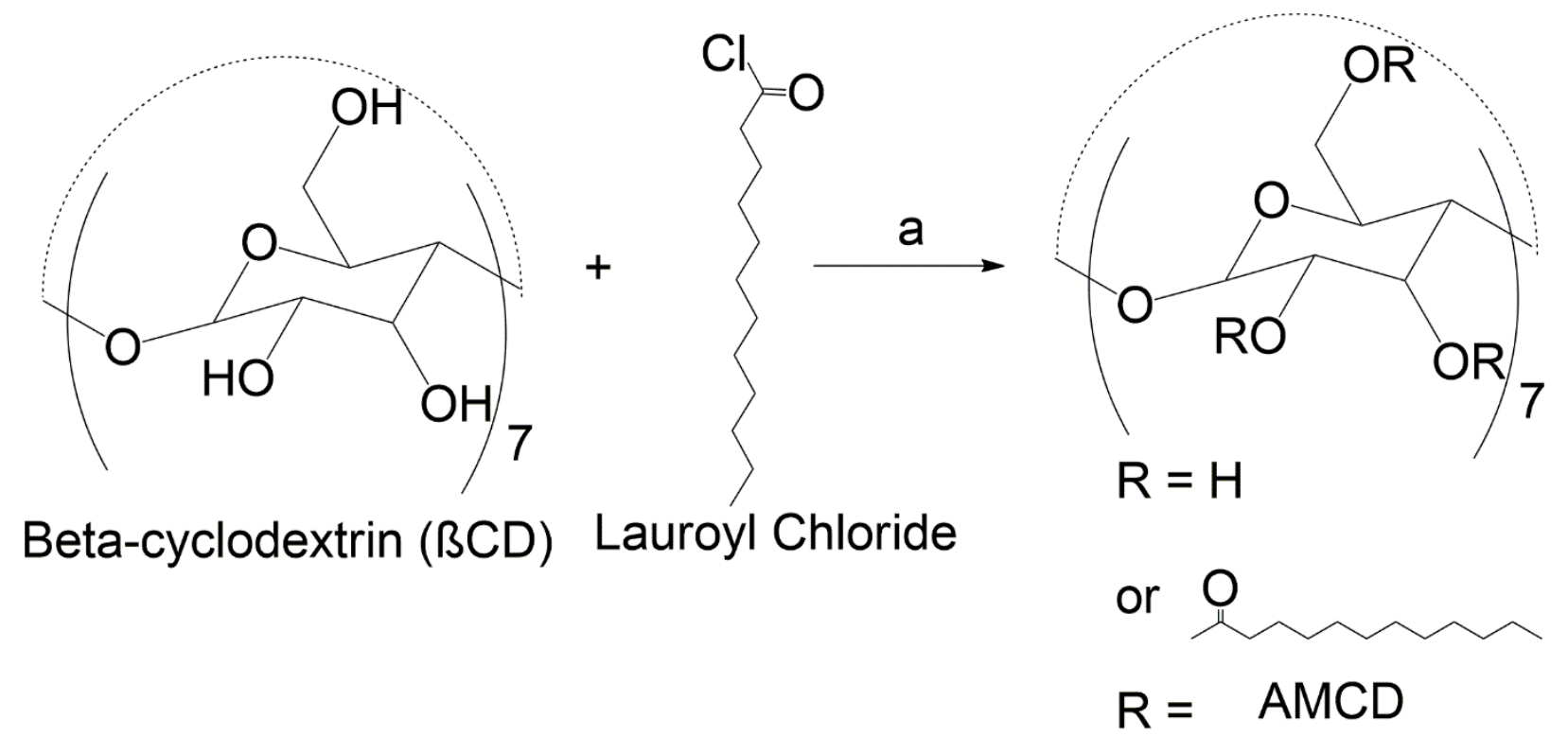


Figure 2
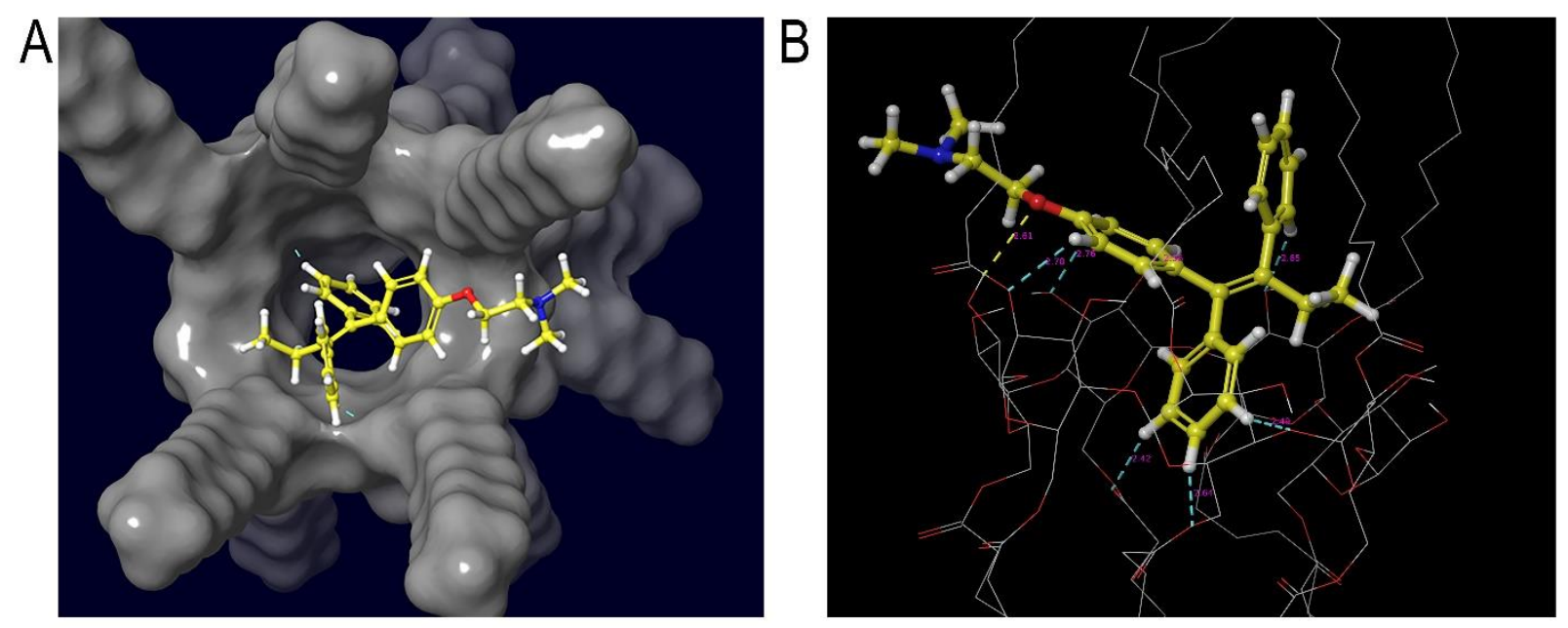

C

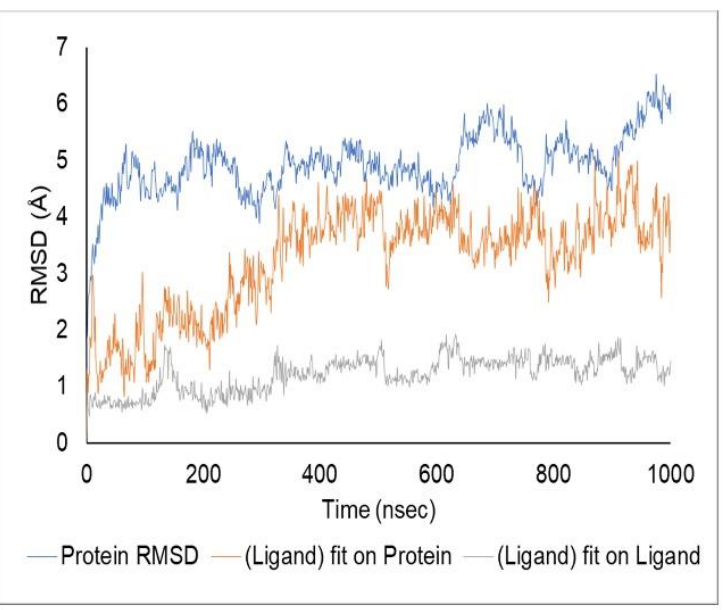

D

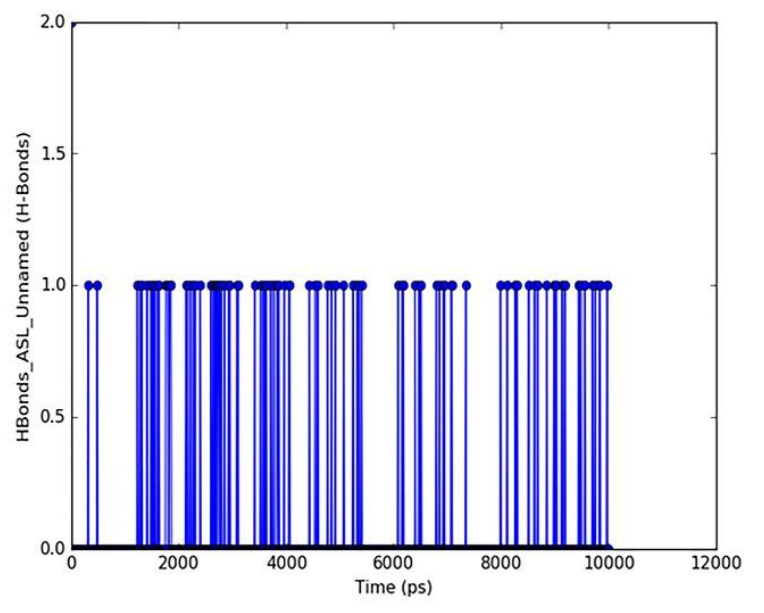


Figure 3 

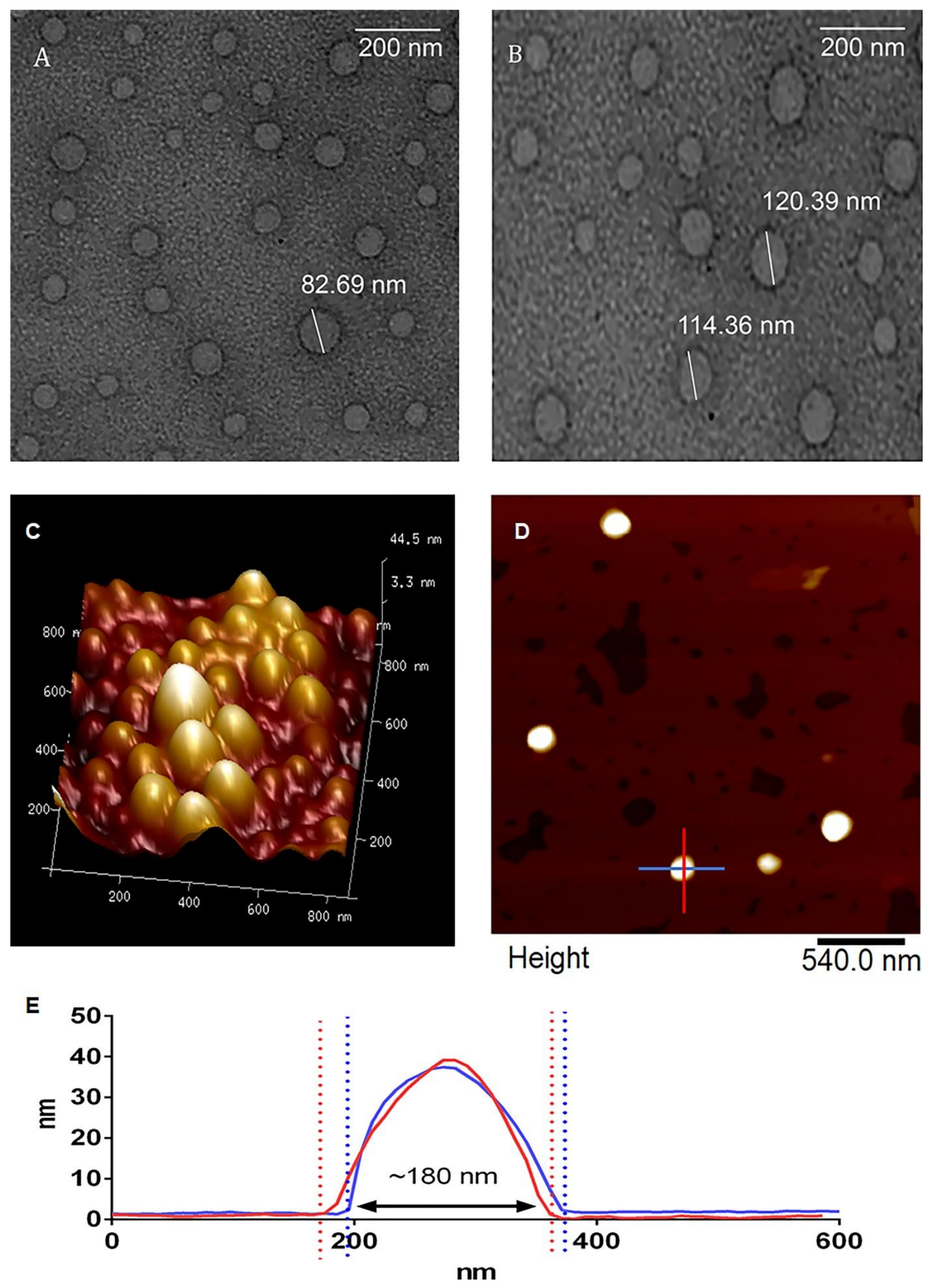

Figure 4
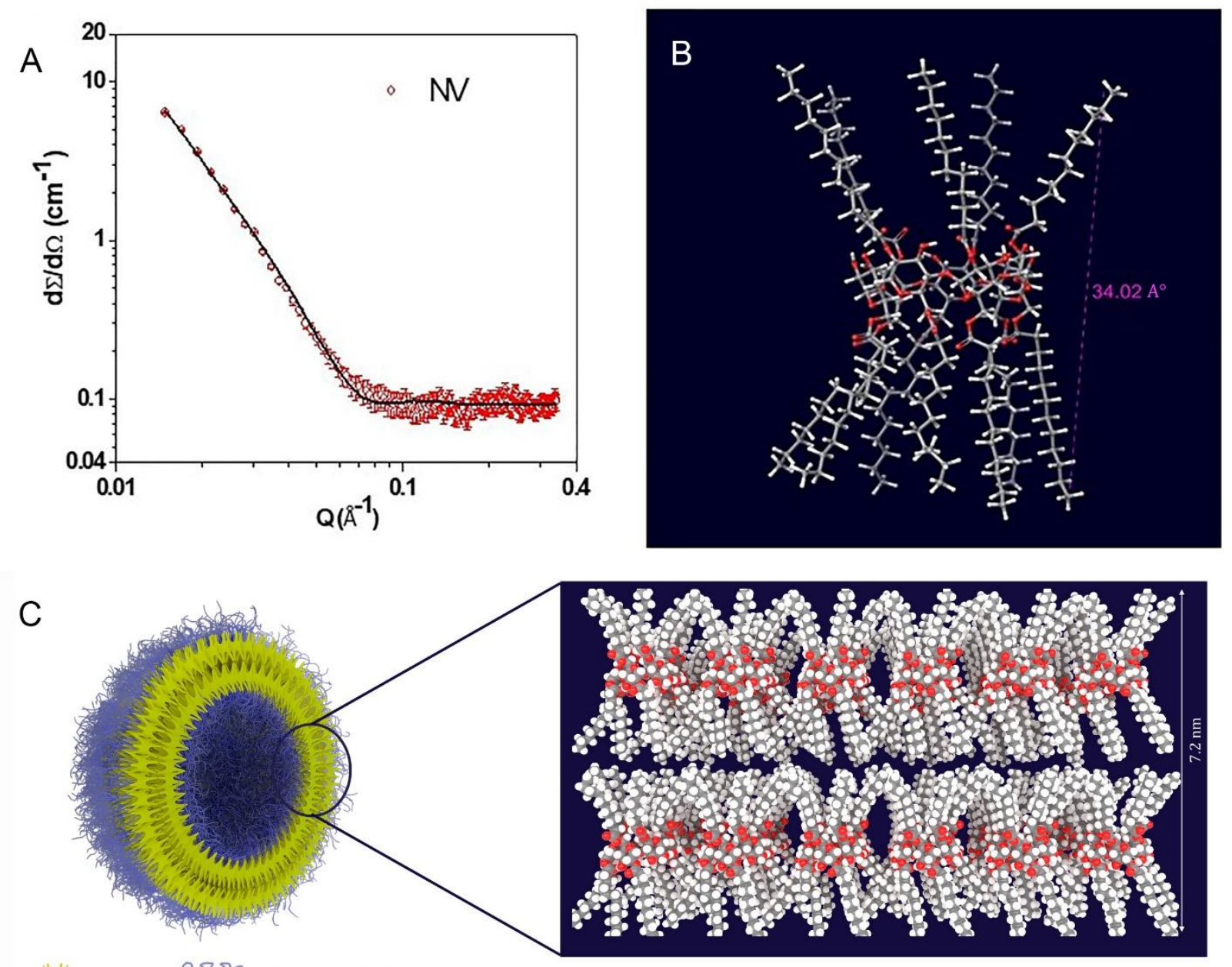

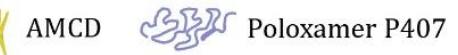


Figure 5

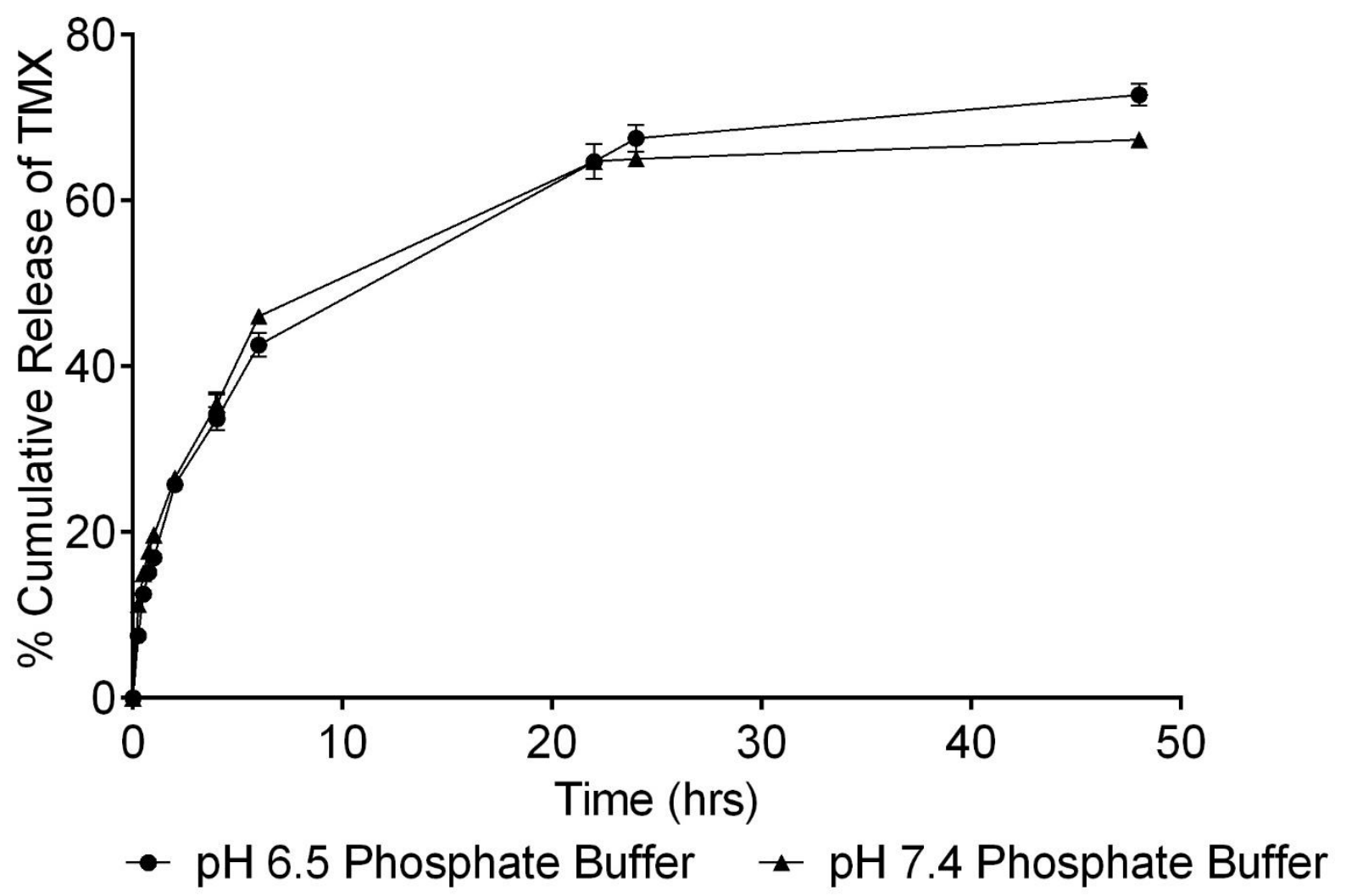


Figure 6

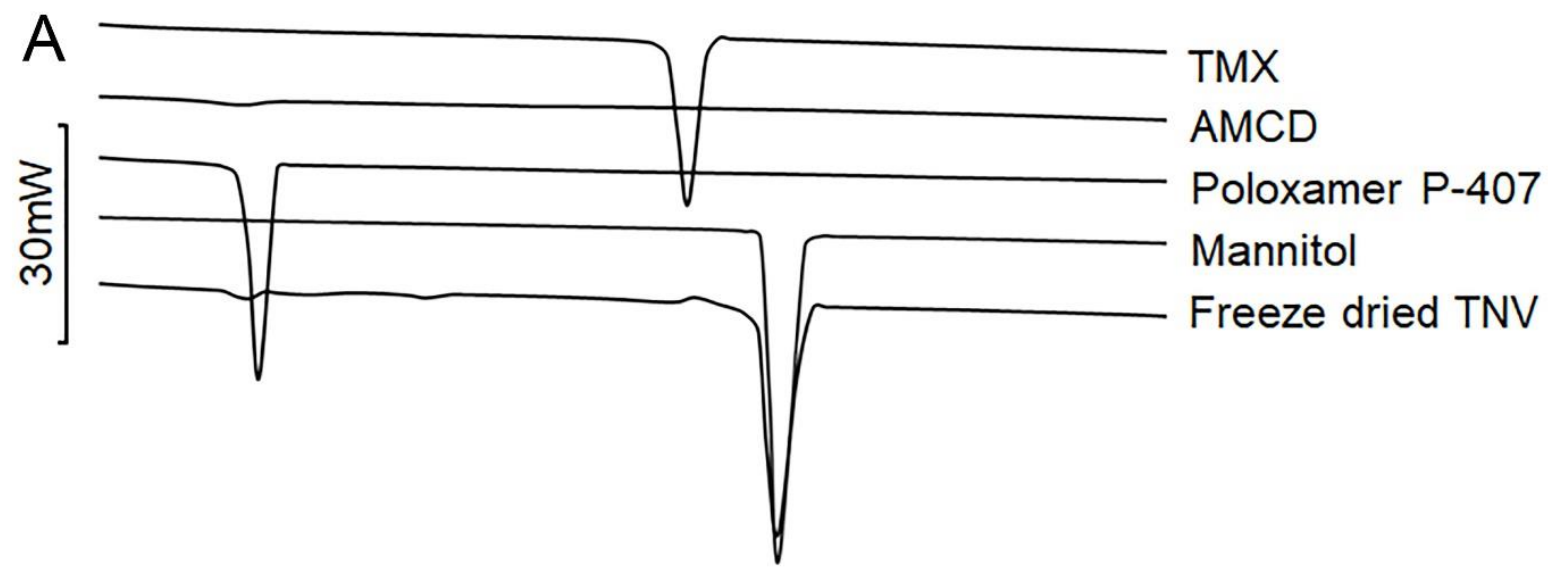

$25 \quad 45 \quad 65 \quad 85105125145165185205225245$

Temperature ${ }^{\circ} \mathrm{C}$

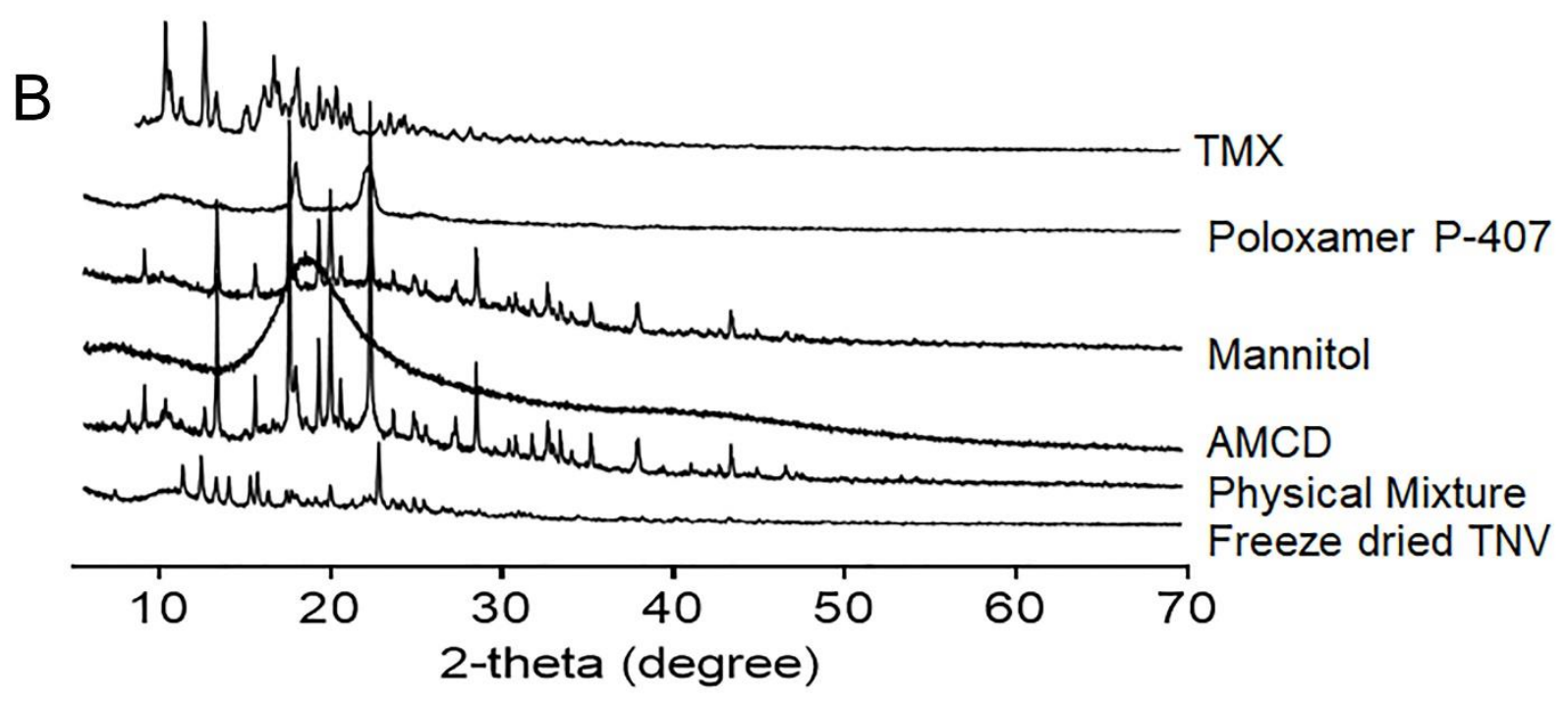




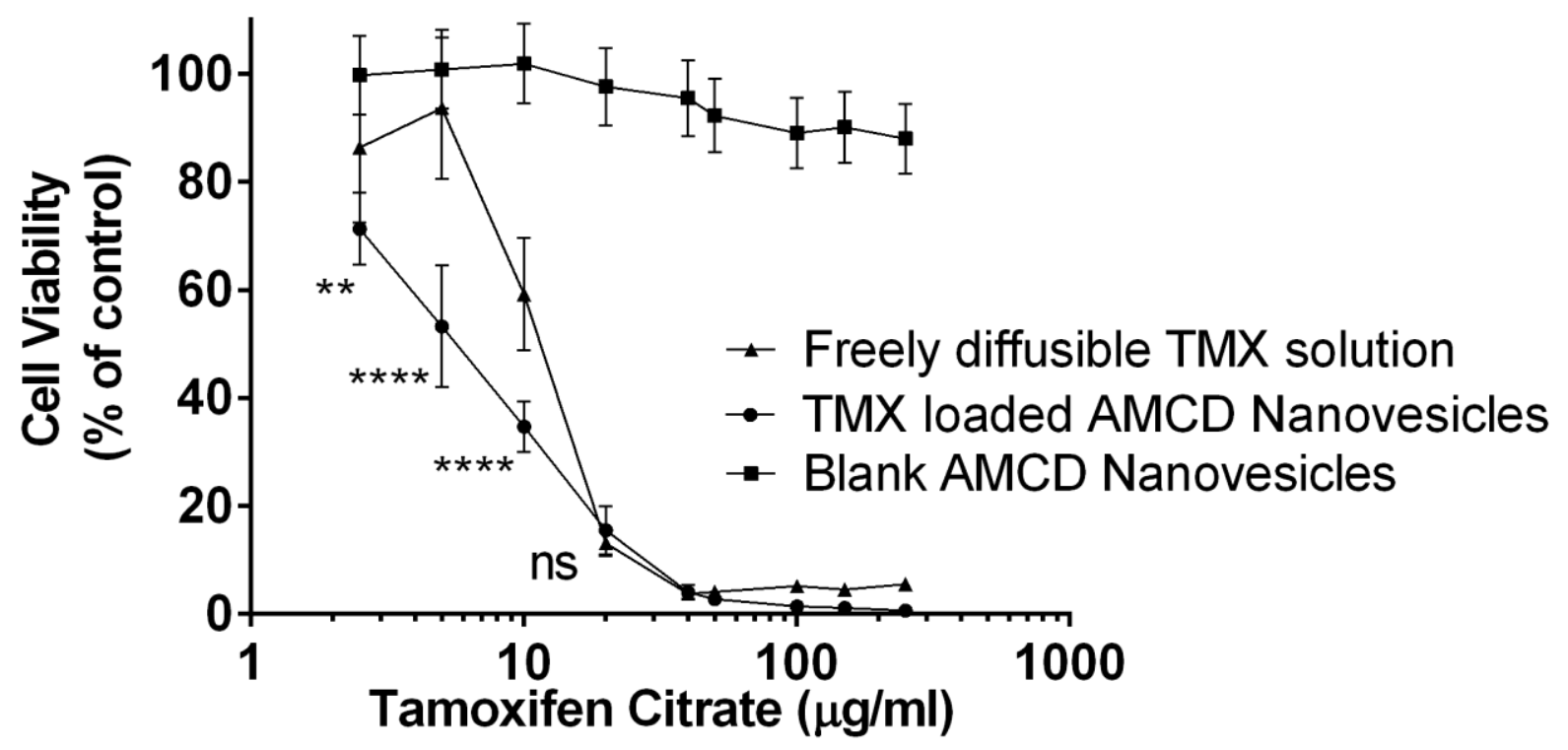


Figure 8
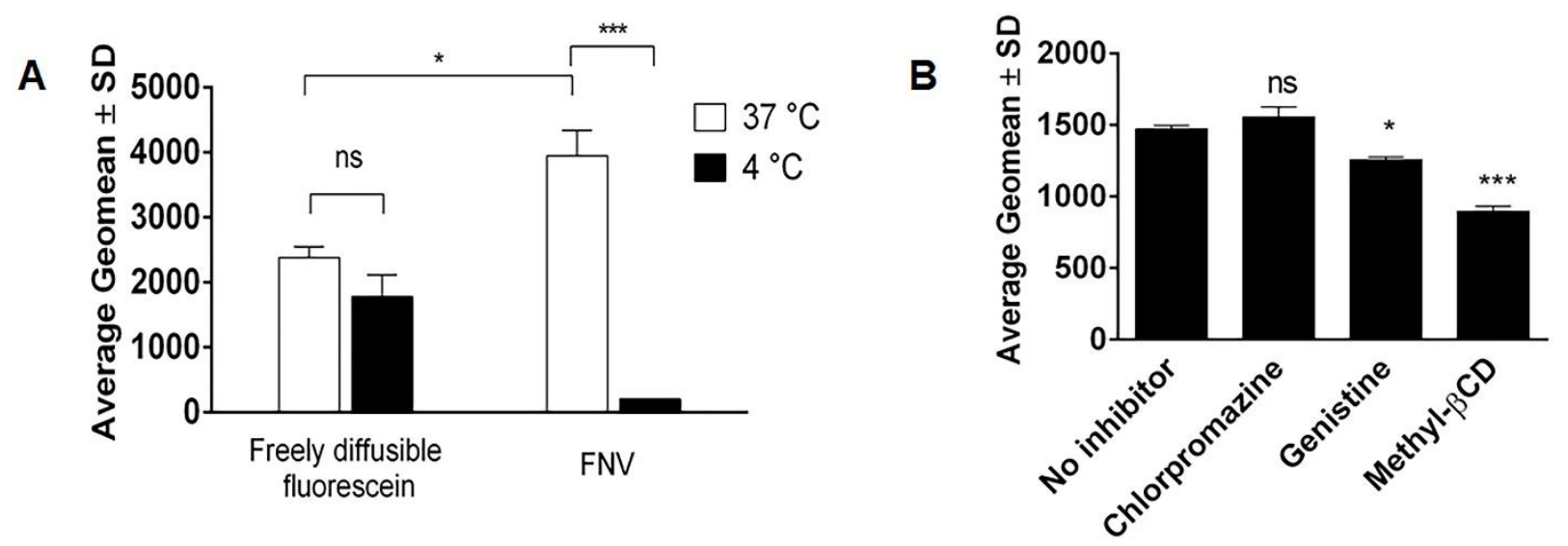
Figure 9

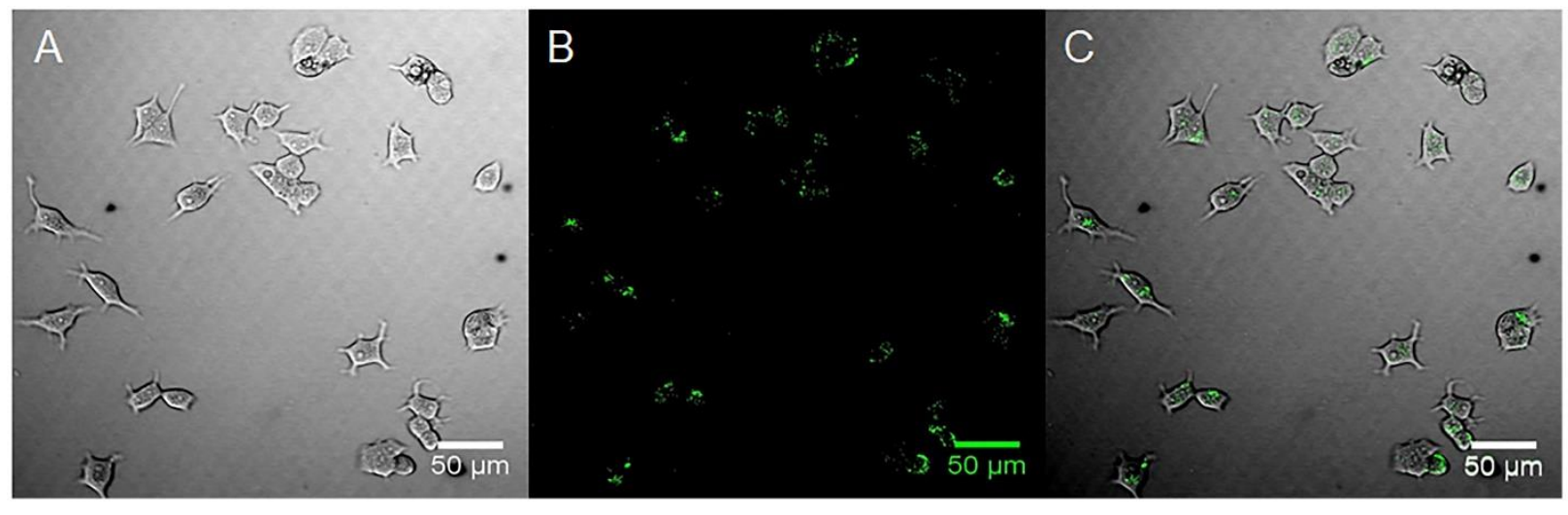


Figure 10

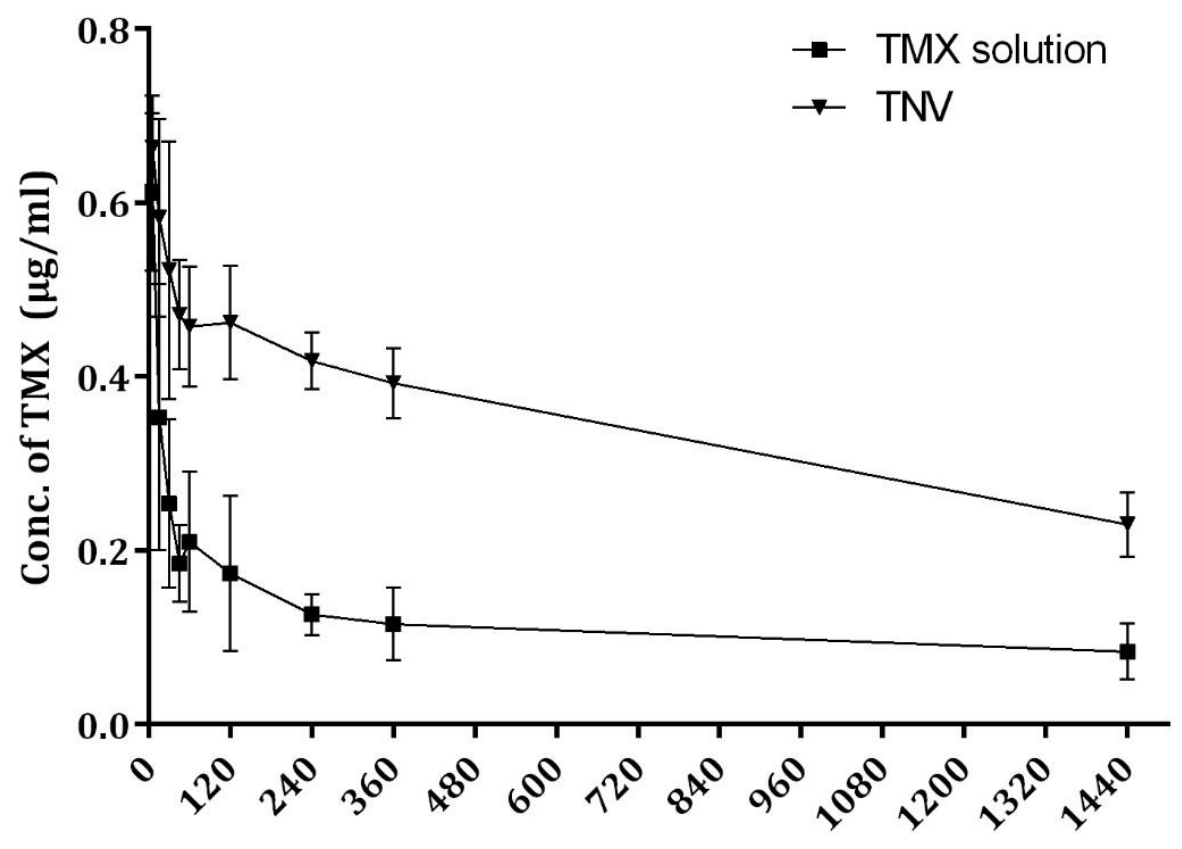

Time (min) 

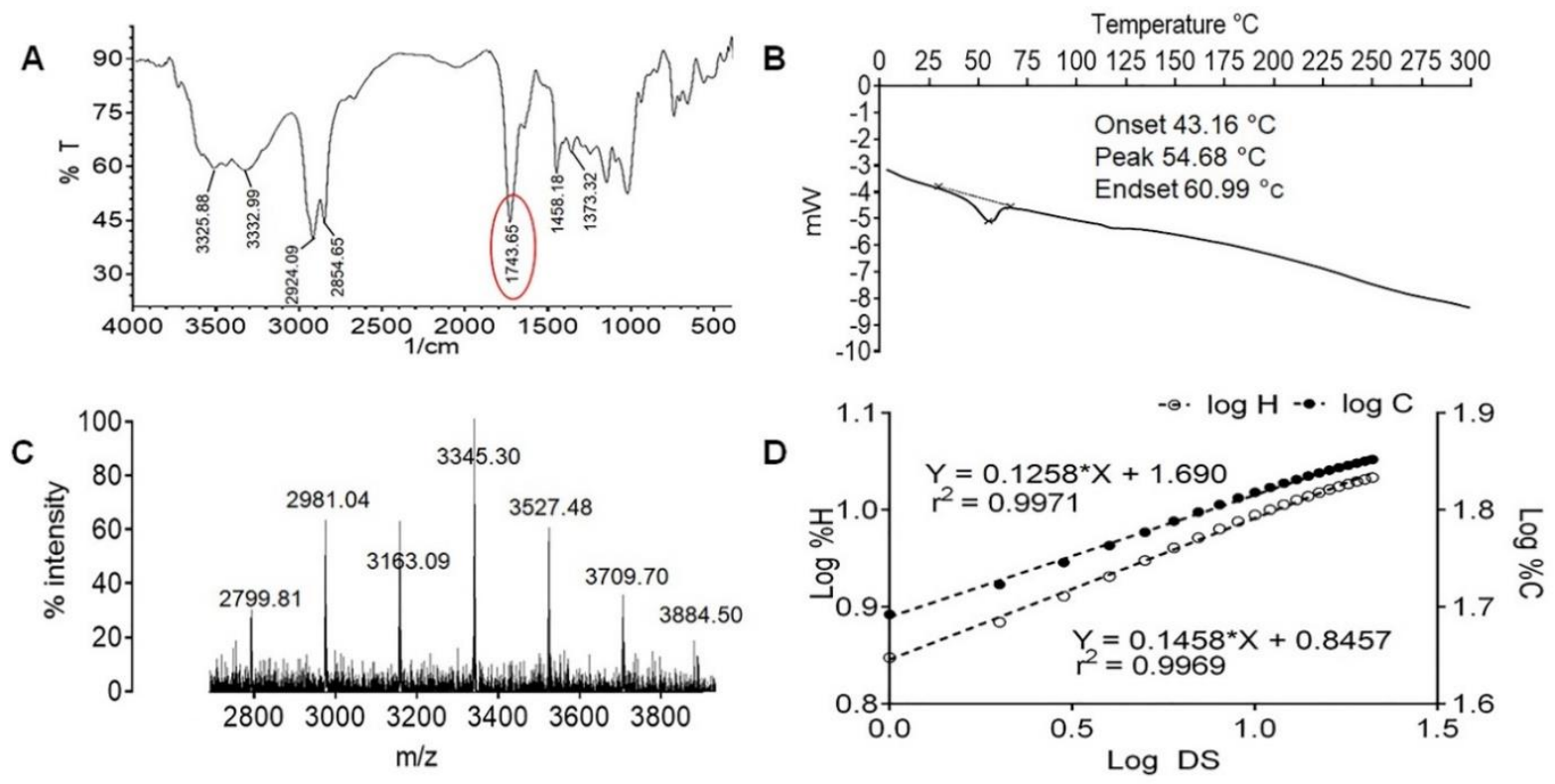

Supplementary figure 1 (A) FTIR spectra of AMCD showing a characteristic peak of ester (B) DSC thermogram of AMCD (C) MALDI-TOF spectra of AMCD showing group of signals corresponding to $\beta C D$-Laurate with 9-15 substitutions (D) Change in $\log \% \mathrm{C}$ and $\log \% \mathrm{H}$ with an increase in $\log \mathrm{Ds}$ of AMCD. 


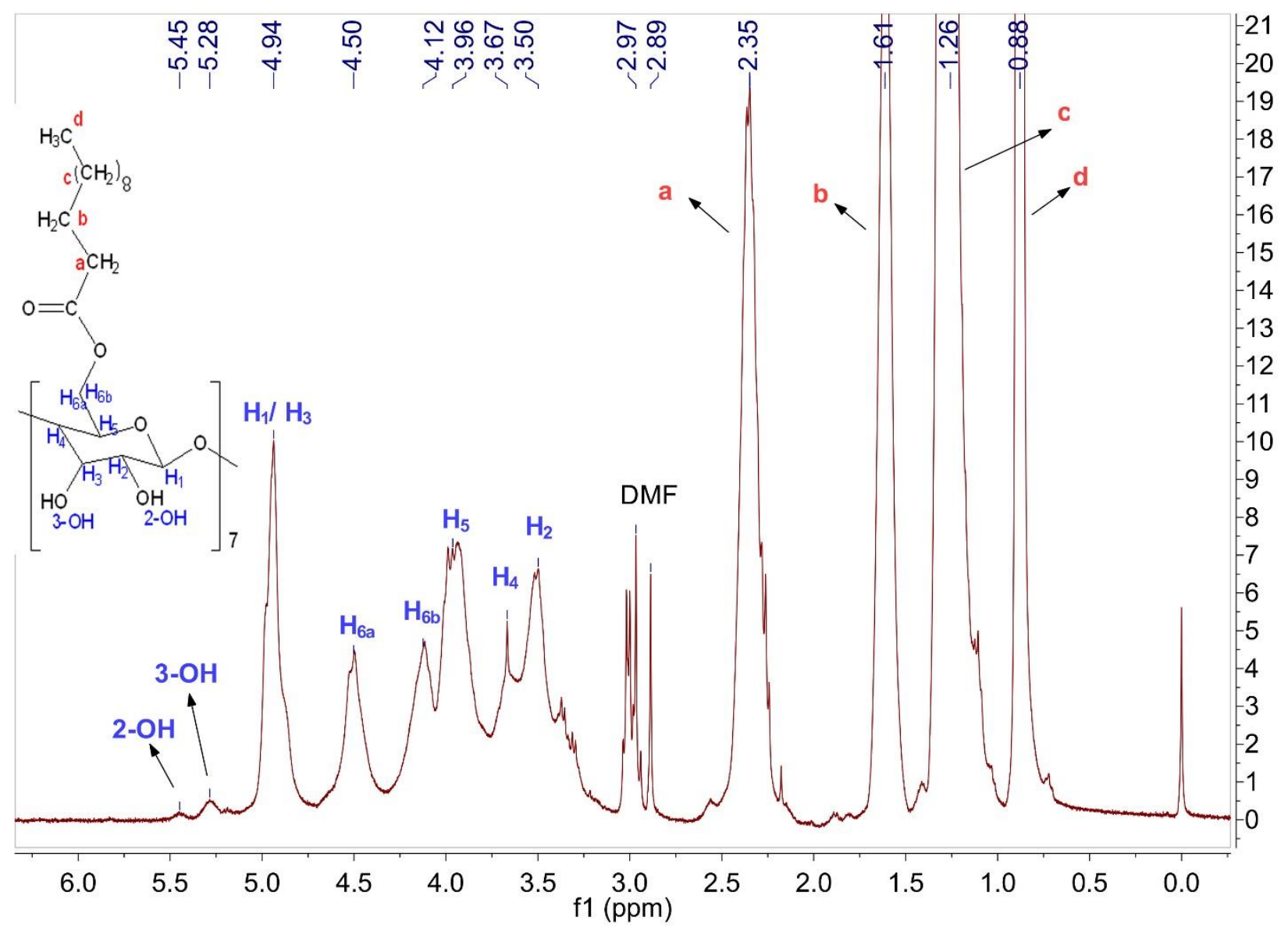

Supplementary figure 2: ${ }^{1} \mathrm{H}-\mathrm{NMR}$ spectrum of synthesized AMCD 


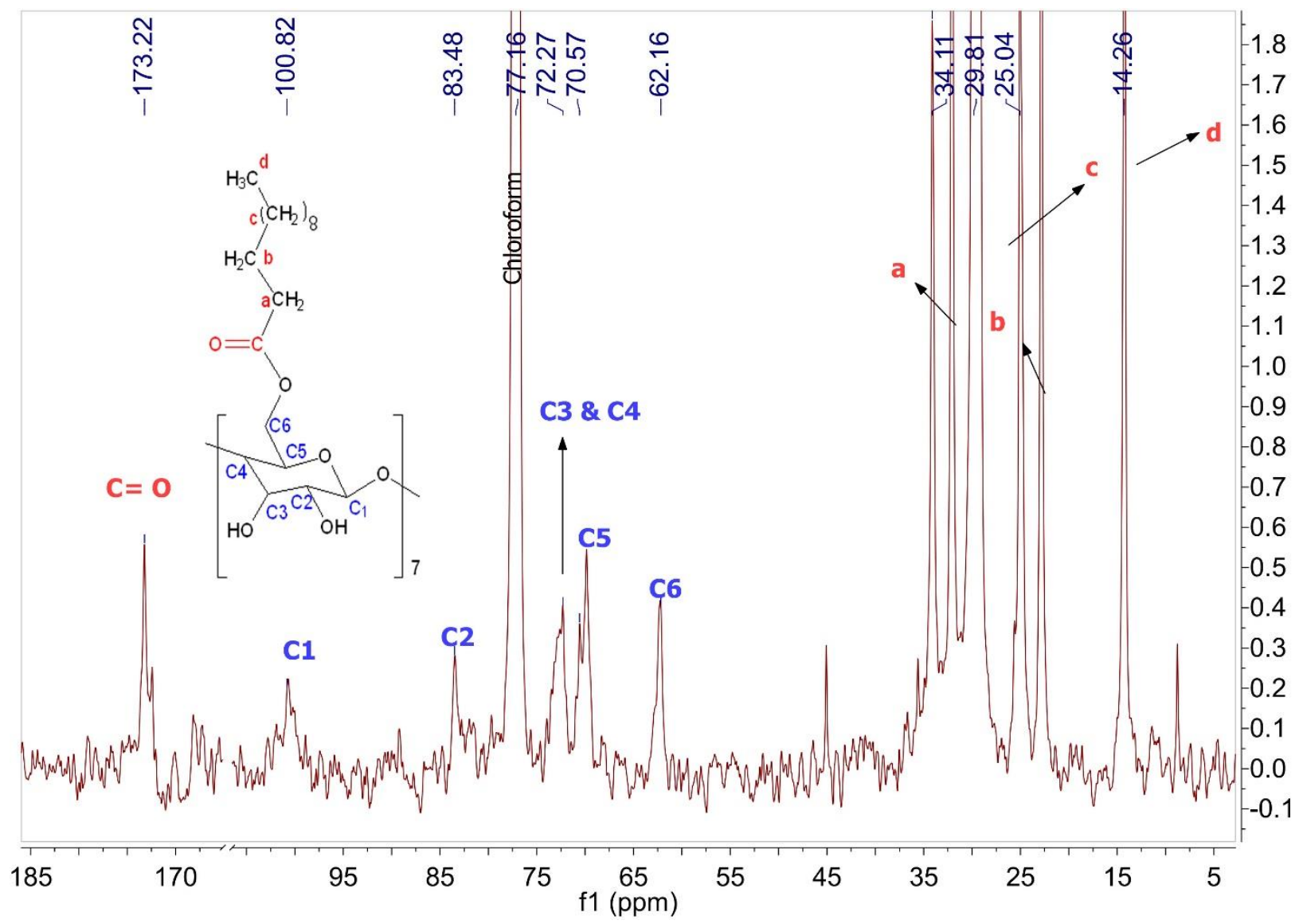

Supplementary figure $3:{ }^{13} \mathrm{C}$-NMR spectrum of synthesized AMCD 


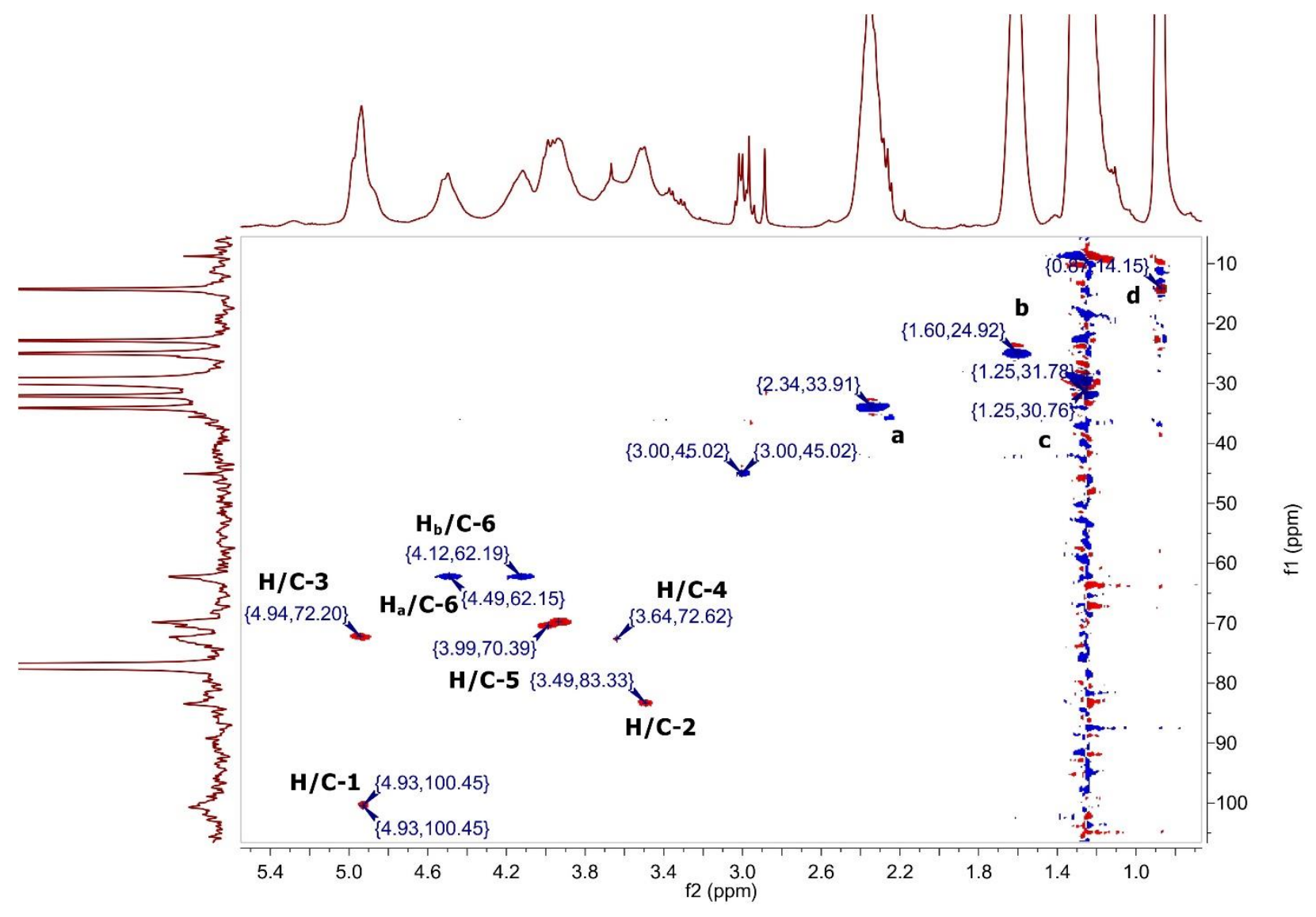

Supplementary figure 4: 2D NMR (HSQC) for synthesized AMCD 


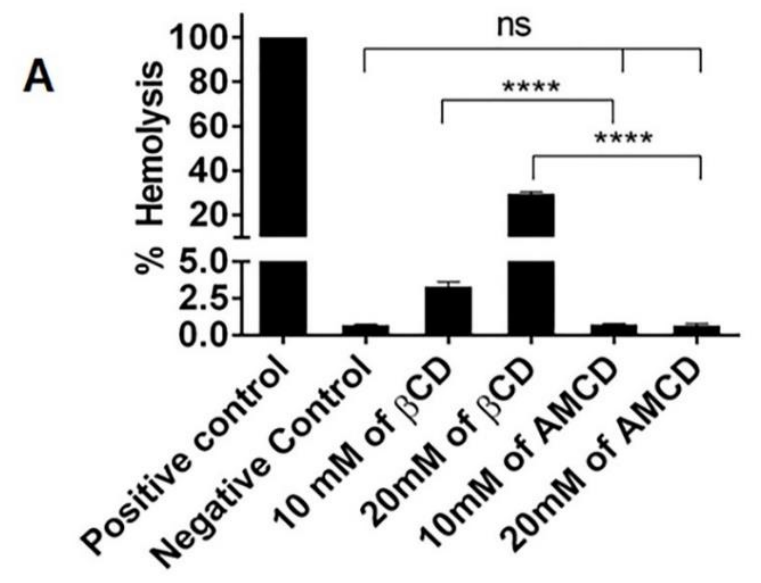

B
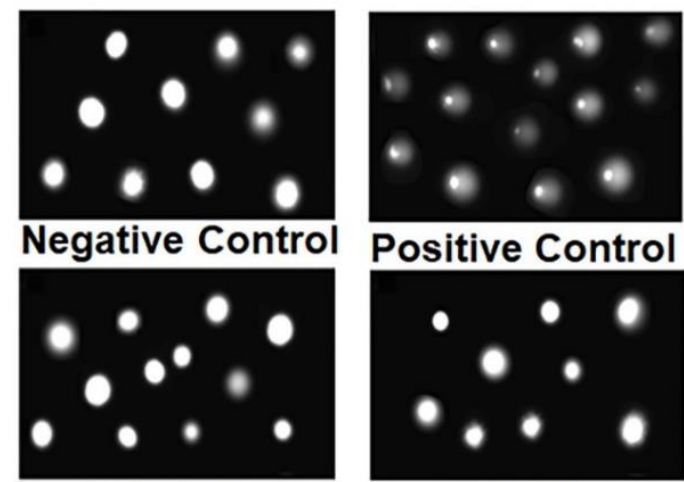

$20 \mu \mathrm{g} / \mathrm{ml}$

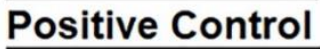

AMCD treated

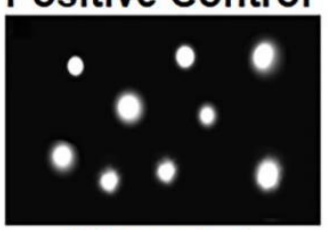

$200 \mu \mathrm{g} / \mathrm{ml}$

AMCD treated

C

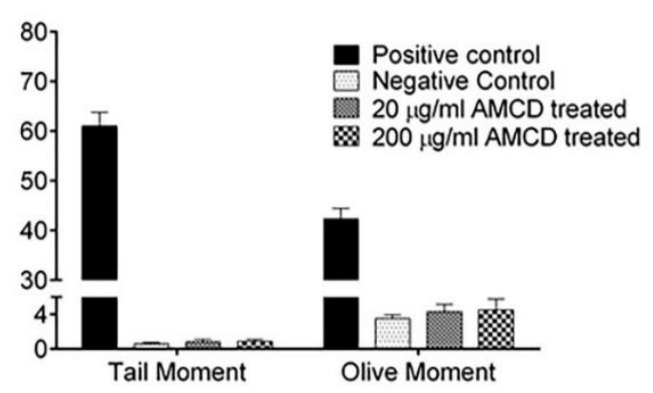

Supplementary figure 5 (A) Hemolysis study on RBC by $\beta C D$ and AMCD at 10 and $20 \mathrm{mM}$ concentrations. (B) Fluorescence microscopy image (20X) of HDMEC cells (C) comet score in HDMEC cells. Data represented as Mean \pm SD of individual duplicate experiments. 

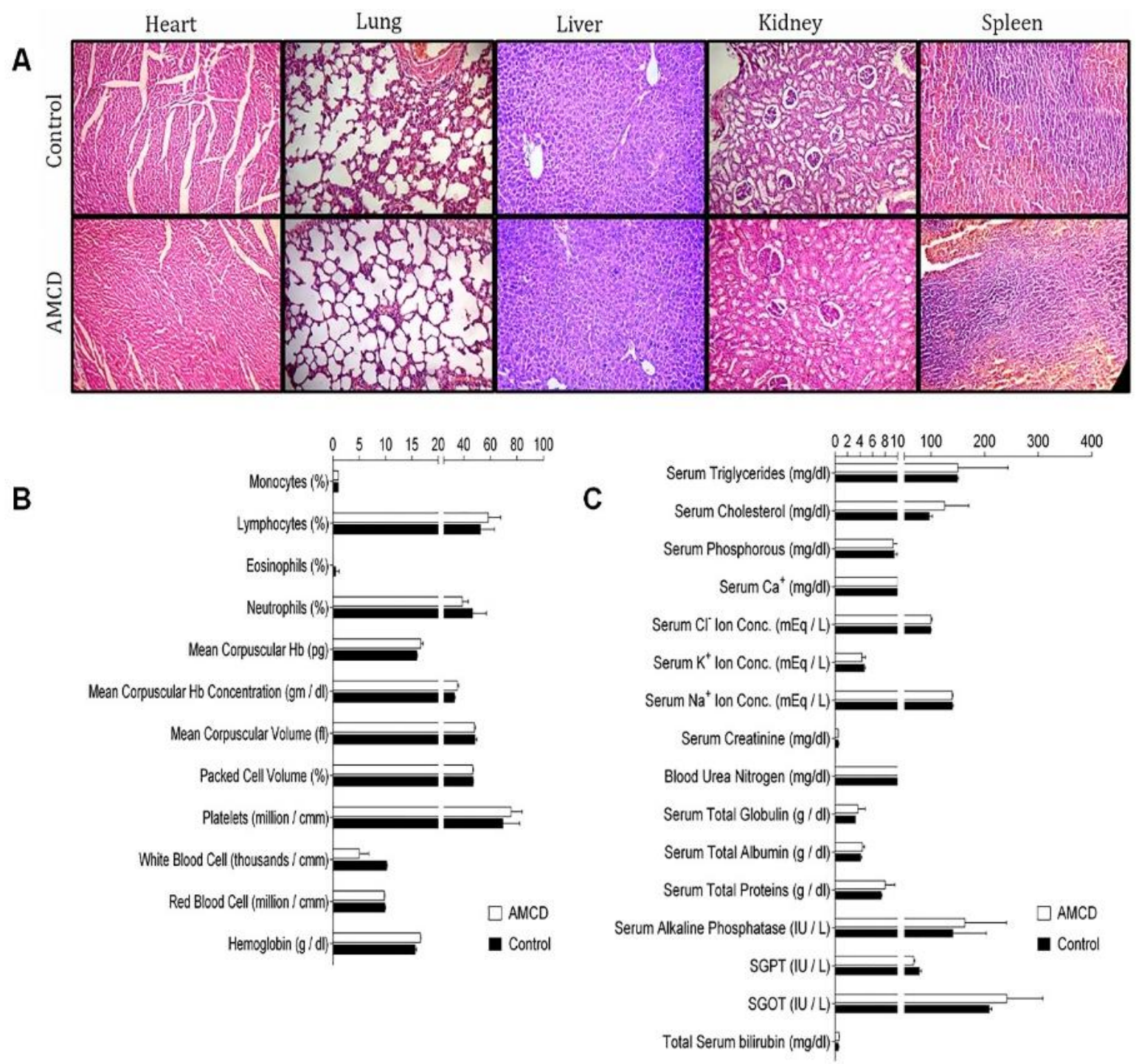

Supplementary figure 6 (A) Histopathology of vital organs of untreated mice and AMCD (2000 mg/kg) treated mice (after 14 days) (B) Haematological parameters of untreated and AMCD (2000 mg/kg) treated mice (after 14 days) (C) Serum Biochemistry of untreated and AMCD (2000 mg/kg) treated mice (after 14 days). Data for blood biochemistry are represented as Mean $\pm \mathrm{SD}(\mathrm{n}=5)$. 